\title{
Processes underlying dimensional interactions: Correspondences between linguistic and nonlinguistic dimensions
}

\author{
ROBERT D. MELARA \\ Purdue University, West Lafayette, Indiana \\ and \\ LAWRENCE E. MARKS \\ John B. Pierce Foundation Laboratory and Yale University \\ New Haven, Connecticut
}

\begin{abstract}
In six experiments, we examined speeded classification when one dimension was linguistic and the other was nonlinguistic. In five of these, attributes on the dimensions corresponded meaningfully, having in common the concepts "high" and "low." For example, in Experiment 1, the visually presented words HI and Lo were paired with high-or low-pitched tones; in Experiment 2, the dimensions were visual words and vertical position, in Experiment 3, they were spoken words and position, and in Experiments 4 and 5, spoken words and pitch. For each dimension in each pair, subjects suffered Garner interference when dimensions were varied orthogonally. Garner interference remained constant across 15 blocks of trials (Experiment 5). Subjects also showed significant congruity effects in all experiments, with attributes from congruent stimuli (e.g., HI/high pitch) classified faster than attributes from incongruent stimuli (e.g., $\mathrm{HI} / \mathrm{low}$ pitch). These results differ from those obtained previously with noncorresponding pairs of linguistic-nonlinguistic dimensions. The results also differ from those obtained with traditional Stroop dimensions (colors and color words; Experiment 6), which showed minimal Garner interference and diminishing congruity effects across blocks of trials. We conclude that the interactions found here represent crosstalk between channels within a semantic level of processing. We contrast our view with current models of dimensional interaction.
\end{abstract}

When classifying attributes on certain pairs of perceptual dimensions, subjects suffer substantial Garner interference (see Pomerantz, 1983, 1986). Garner interference is defined as slower performance to classify attributes on Dimension A when attributes on Dimension B are varied orthogonally than when attributes on Dimension $B$ are held constant. Or, alternatively, Garner interference occurs when subjects perform worse in a filtering task (irrelevant dimension varied orthogonally) than they do in a baseline task (irrelevant dimension held constant). Originally, Garner (1974b) distinguished two types of perceptual dimensions on the basis of how subjects perform in these speeded classification tasks. Perceptually integral dimensions, such as saturation and brightness of colors

Preparation of this article was supported by National Institutes of Health (NIH) Postdoctoral Fellowship HD07137 and NIH Grant NS28617 to Robert Melara and by NIH Grant DC00271 and National Science Foundation Grant BNS84-20017 to Lawrence Marks. We thank Margaret Jean Intons-Peterson, Linda Smith, Daniel Algom, Bonnie Potts, and two anonymous reviewers for their helpful comments on an earlier version of the paper. We also thank Ed Washecka, Trex Proffitt, and Alison Wittenberg for their assistance in collecting and analyzing the data. Address all correspondence to Robert D. Melara, Department of Psychological Sciences, Purdue University, West Lafayette, IN 47907.
(Garner \& Felfoldy, 1970), produce significant Garner interference. Separable dimensions, such as the size of a circle and the orientation of its diameter (Garner \& Felfoldy, 1970), produce little or no Garner interference.

Recently, Garner interference has been found with pairs of dimensions unlike the integral dimensions studied originally. For example, Garner interference has been found with configural dimensions, such as parentheses stimulithat is, the four possible stimuli created by pairing leftand right-facing parentheses (Pomerantz \& Garner, 1973; see also Garner, 1976). Pomerantz (1986; Pomerantz \& Pristach, 1989; Pomerantz, Pristach, \& Carson, 1989) has argued that, unlike integral dimensions, configural dimensions produce Garner interference because subjects perceive and actively use salient emergent properties present in these stimuli. Configural dimensions are one example, then, of dimensions that interact (i.e., yield Garner interference) but are not integral.

Melara (1989a, 1989b; Melara \& O'Brien, 1987) has recently uncovered another example of interacting dimensions, namely cross-modally (synesthetically) corresponding dimensions. Melara and O'Brien (1987), for example, tested the synesthetically corresponding dimensions of vertical position (of visual stimuli) and pitch (of auditory stimuli) in speeded classification. Under a variety of 
conditions, and for each dimension considered separately, substantial Garner interference obtained. These results were replicated later (Melara, 1989a) in experiments with the dimensions color (white, black) and pitch (high, low). In addition to Garner interference, both position-pitch and color-pitch yield substantial congruity effects (or what Pomerantz, 1983, calls "Stroop-type interference"): Subjects classify stimuli containing corresponding attributes (e.g., white/high or black/low) faster than they classify stimuli containing noncorresponding attributes (e.g., white/low or black/high; see also Marks, 1987).

The presence of robust congruity effects is one trademark of interaction between corresponding dimensions. Such congruity effects are frequently absent in tests of integral dimensions (but see Melara \& Marks, 1990c). Thus, these effects suggest that corresponding dimensions, like configural dimensions, interact in a way different from integral dimensions. The mechanisms underlying the Garner interference and congruity effects that earmark these correspondence interactions are poorly understood. One purpose of this article is to elucidate these mechanisms. As will be discussed later, our findings with corresponding dimensions also bear strongly on general theoretical models of dimensional interaction.

\section{Crosstalk in Correspondence Interactions}

In this article, we continue our attempts (see, e.g., Melara \& Marks, 1990a, 1990d) to identify the directions and levels of crosstalk (Pomerantz et al., 1989) between separate processing channels. We presume that, on each trial of a classification task, values on Dimension A (or B) undergo several meaningfully distinct levels of analysis before the subject initiates a classificatory response. Possible levels are indicated in each panel of Figure 1. With certain pairs of dimensions, such as the color dimensions of saturation and brightness (see Panel A of Figure 1), crosstalk presumably occurs within a sensory/ perceptual level of processing (see, e.g., Foard \& Kemler Nelson, 1984). The crosstalk between color dimensions is bidirectional (depicted as a two-way street), because orthogonal variation in saturation causes as much Garner interference in classifying brightness as variation in brightness causes in classifying saturation (e.g., Garner \& Felfoldy, 1970).

What is the nature of crosstalk between synesthetically corresponding pairs of dimensions? Several pieces of evidence suggest that crosstalk between these dimensions may also occur within a sensory/perceptual level of processing. First, the cross-modal correspondences experienced by synesthetes appear to have a sensory/ perceptual origin. Synesthetes are individuals who, when presented with, say, an auditory attribute (e.g., a 1000-Hz tone), report that they perceive a corresponding attribute from a separate sensory modality (e.g., a yellow hue). The immediacy, clarity, consistency, and realism of these experiences suggest that synesthetic experiences may arise from perception-like processes (Calkins, 1895; Karwoski \& Odbert, 1938; Luria, 1968; Ortmann, 1933; Riggs \&
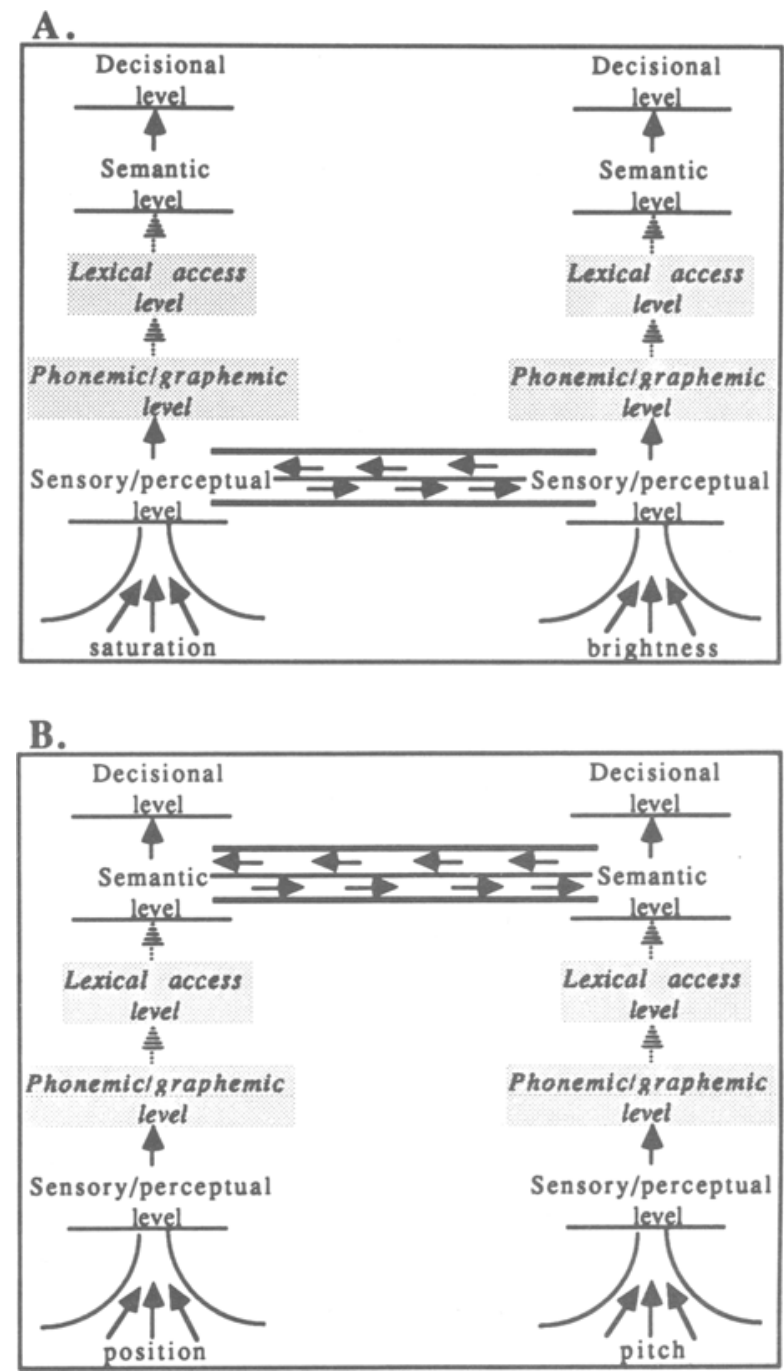

Figure 1. Pictorial interpretation of processes underlying the integrality of saturation and brightness (Panel $A$ ) and those underlying the symmetric interaction between synesthetically corresponding position and pitch (Panel B) (see text for details). Note-Arrows indicate the hypothesized flow of processing from one level of analysis to another, either during analyses of any one dimension or when crosstalk occurs between two dimensions. Labels have been masked for the linguistic analyses (i.e., lexical access level, phonemic/ graphemic level), which are presumed to be disengaged when processing these perceptual dimensions.

Karwoski, 1934; see also Marks, 1975; Melara \& O'Brien, 1987). Importantly, the correspondences experienced by synesthetes are frequently identical to the crossmodality matches made by nonsynesthetes in psychophysical matching studies (e.g., Odbert, Karwoski, \& Eckerson, 1942; Riggs \& Karwoski, 1934). Indeed, reliable cross-modal correspondences from nonsynesthetes have been found in young children (e.g., Marks, Hammeal, \& Bornstein, 1987) and even in preverbal infants (e.g., Lewkowicz \& Turkewitz, 1980; Wagner, Winner, 
Cicchetti, \& Gardner, 1981). Some researchers have suggested that if the correspondences of synesthetes are sensory/perceptual in origin, then perhaps similar perceptual mechanisms structure the synesthetic correspondences of ordinary nonsynesthetic subjects (see Hornbostel, 1927; Marks, 1975; Melara \& O'Brien, 1987; Werner, 1940).

Perhaps a more compelling reason to believe that corresponding dimensions interact at a sensory/perceptual level is the fact that Garner interference itself is found with these dimensions. The presence of Garner interference is explained typically as a failure of selective attention due to a perceptual fusion of dimensional attributes. Consider, for example, the color dimensions of saturation and brightness. These dimensions yield significant Garner interference (Garner \& Felfoldy, 1970). In addition, when similarity ratings of stimuli formed from these dimensions are subjected to a multidimensional scaling analysis, scale values are fit best by a Euclidean metric; judgments of stimuli formed from separable dimensions are described best by a city-block rule (e.g., Handel \& Imai, 1972; Hyman \& Well, 1967, 1968; Torgerson, 1958; see also Garner, 1974b). According to the prevailing view, these results obtain because color stimuli are perceived as wholes, or "blobs"' (Garner, 1974b, 1981; Lockhead, 1966, 1972, 1979; see also Foard \& Kemler Nelson, 1984; Kemler 1983a, 1983b; Shepp, 1989; Smith \& Kemler, 1977); that is, the component dimensions of saturation and brightness are not perceived initially. Thus, the better fit of a Euclidean metric over a city-block metric occurs, in this view, because color stimuli are compared on the basis of their overall similarity and not on the basis of the similarity of values on individual dimensions. Likewise, Garner interference with color dimensions is thought to result from the attentional effort required to analyze each stimulus whole into its component attributes (Shepp, 1989; Smith \& Kemler, 1978).

This sensory/perceptual account could also be applied to correspondence interactions. Like color dimensions, corresponding dimensions lead to Garner interference in speeded classification (Melara, 1989a; Melara \& O'Brien, 1987) and lead to a Euclidean metric in similarity scaling (Melara, 1989b). Thus, it is conceivable that correspondence interactions are localized at a sensory/perceptual level of processing where the separate dimensions have not (yet) been well articulated psychologically. For purposes of this article, we will define sensory/perceptual crosstalk between corresponding dimensions as owing to such holistic processes, that is, to the mutual influence of two channels at an early level of dimensional processing.

\section{Semantic Crosstalk}

Despite evidence favoring traditional holistic models (see Kemler Nelson, 1989, for a review), recent findings suggest that these accounts may inadequately explain correspondence interactions. Melara (1989b) argued that if corresponding dimensions interacted exclusively at a sensory/perceptual level, then this implies that perceivers represent stimuli comprising corresponding attributes (e.g., high position/high pitch and low position/low pitch) farther apart from each other in psychological space than they represent stimuli comprising noncorresponding attributes (e.g., high/low and low/high). Greater perceptual distance separating congruent stimuli fits well the finding that these stimuli are discriminated from each other faster than are stimuli comprising noncorresponding attributes (Marks, 1987; Melara, 1989a; Melara \& O'Brien, 1987). Unfortunately, in his multidimensional scaling analysis, Melara (1989b) found no evidence that subjects represent cross-modally corresponding stimuli at different perceptual distances. He concluded that models that explain correspondence interactions as sensory/perceptual crosstalk, at least in its strong form, are incorrect. By implication, later levels of processing may be involved.

Clark and Brownell's $(1975,1976)$ work with visual dimensions also implicates crosstalk at later levels. These investigators used arrows as stimuli to test for interactions between arrow direction (up or down) and vertical position (high or low). Subjects suffered significant Garner interference when classifying either of these dimensions. And, as with the cross-modal dimensions, subjects displayed significant congruity effects: Stimuli comprising congruent attributes were classified faster than were stimuli comprising incongruent attributes. Note that the correspondence between an arrow's direction and its position is likely to be a learned one involving comparison among abstract units of meaning. Thus, the Garner interference found here suggests a possible role for higher level cognitive processes.

Given the ubiquitous appearance of congruity effects with both the cross-modal stimuli studied by us (Marks, 1987; Melara, 1989a; Melara \& O’Brien, 1987; see also Walker \& Smith, 1984, 1986) and the unimodal stimuli studied by Clark and Brownell $(1975,1976)$, it seems reasonable to posit that correspondence interactions may be semantically based, at least in part. In this view, correspondence interactions between two channels reflect the effect of operations in one channel on the extraction of meaning units in the other channel. For purposes of this article, we call mutual influences between two channels localized within a semantic level of processing semantic crosstalk. In Panel B of Figure 1, we depict the possibility that Garner interference (and effects of congruity) obtained in classifications of vertical position and auditory pitch (Melara \& O'Brien, 1987) emerge from bidirectional semantic crosstalk. We recognize that this representation is premature at present; our purpose in these experiments was to evaluate the adequacy of this model.

\section{Purpose of These Experiments}

In this study, we investigate whether interactions between corresponding dimensions can occur within a semantic level of processing in adult subjects. We accomplish this by pairing a linguistic dimension (words) with a corresponding nonlinguistic dimension (e.g., auditory pitch), and testing classification of each dimension in 
Garner's paradigm. Here is our logic: If crosstalk between corresponding dimensions is sensory/perceptual, then variation on a linguistic dimension should not cause Garner interference in a corresponding nonlinguistic dimension. Conversely, if analysis at a logically later (linguistic) level causes Garner interference in classification of dimensions analyzed at a logically earlier (sensory/ perceptual) level, then crosstalk cannot be based exclusively in sensory/perceptual influences. By our assumptions, then, the presence of Garner interference in the nonlinguistic dimension implies crosstalk either between sensory/perceptual and semantic levels or within the semantic level alone. And, if significant effects of congruity obtain in both members of the linguistic-nonlinguistic pairs, we assume that crosstalk was restricted to the semantic level. Thus, finding the full pattern-Garner interference and congruity effects in both the linguistic and the nonlinguistic dimension-implies crosstalk within a semantic level of processing.

Note, however, that the full pattern could also obtain if perceptual characteristics of the words interacted with perceptual characteristics of the nonlinguistic attributes (e.g., pitches). We address this alternative explanation in this study by testing several pairs of corresponding dimensions. If several different cases of interaction between a linguistic and a nonlinguistic dimension can be documented, then this sensory/perceptual account of interaction becomes progressively less convincing, and the semantic account that much more convincing.

Previous research by Wood (1974, 1975; Day \& Wood, 1972) suggests that linguistic dimensions may not affect classification of nonlinguistic dimensions. When testing paired linguistic attributes (stop consonants of consonantvowel syllables) and nonlinguistic attributes (pitch of the vowel phoneme) in speeded classification, Wood (1975) found asymmetric interaction: Orthogonal variation of the nonlinguistic dimension caused interference in classifying the linguistic dimension, but no Garner interference obtained in classifying the nonlinguistic dimension. Wood's finding implies that crosstalk was unidirectional and upstream, that is, from the sensory/perceptual level to a phonemic/graphemic level. If a similar asymmetry of interaction obtains between corresponding linguisticnonlinguistic dimensions, we regard it as strong evidence that correspondence interactions have a sensory/perceptual basis. This conclusion would be bolstered if congruity effects were absent or, at least, were limited to classification of the linguistic dimension.

In this article, we examine four different pairings of a linguistic dimension with a corresponding nonlinguistic dimension. The linguistic attributes appear either visually or aurally, depending on the experiment, but, in each case, the dimension comprises the word attributes high and low. The nonlinguistic member of each pair is one whose attributes are labeled "high" and "low." In vision, this dimension is vertical position (Experiments 1 and 3 ); in audition, this dimension is pitch (Experiments 2,4 , and 5). The present series of experiments are thus directly comparable to Melara and O'Brien's (1987) experiments, with the nonlinguistic pairs vertical position and pitch. In each case, we find strong evidence for symmetric interaction. Also, the effects are stable across blocks of trials. Moreover, we find that cognitive processing of these corresponding dimensions is unlike processing of the traditional Stroop dimensions, colors and color names. On the basis of this evidence, we will conclude that these and perhaps all correspondence interactions differ qualitatively from other forms of dimensional interaction, because Garner interference with corresponding dimensions is rooted in semantic crosstalk.

\section{EXPERIMENT 1}

\section{Visual Words and Pitch}

Melara and O'Brien (1987) demonstrated that the nonlinguistic dimensions of vertical position and pitch interact in speeded classification. The pattern of results was new. In addition to finding Garner interference and effects of congruity, Melara and O'Brien found that subjects performed differently depending on how the dimensions were correlated. If dimensions were correlated positively (i.e., if the task required discriminating high position/high pitch from low position/low pitch), subjects displayed a "redundancy gain." In other words, this discrimination was made significantly faster than were any of the baseline discriminations. On the other hand, if the dimensions were correlated negatively (i.e., if the task required discriminating high position/low pitch from low position/high pitch), subjects performed no better than baseline. These results were unlike those found with typical integral dimensions, for which both correlateddimension tasks show redundancy gain (Garner \& Felfoldy, 1970). The results were also unlike those found with configural dimensions, for which only negatively correlated dimensions lead to redundancy gain (Pomerantz \& Garner, 1973). Note that, with Melara and O'Brien's dimensions, the positively correlated stimulus set contains the two synesthetically congruent stimuli, whereas the negatively correlated stimulus set contains the two incongruent stimuli. Thus, differences between dimensional correlations, like the effects of congruity, can be attributed to the polar correspondence of dimensional attributes.

In Experiment 1, we paired the visually presented words $\mathrm{HI}$ and LO with high- and low-pitched tones. We tested these dimensions in the full speeded classification paradigm-baseline, filtering, and correlated-dimensions tasks. Is performance with words and pitch similar to the pattern of performance obtained previously with position and pitch? Does Garner interference obtain? Is there an effect of congruity? Finally, is performance with positively correlated dimensions superior to that with negatively correlated dimensions?

\section{Method}

Subjects. Twenty subjects (10 men and 10 women), mostly students recruited from the Yale community, were paid $\$ 5$ per hour to participate. 
Stimuli and Apparatus. Auditory attributes were high- and lowpitched complex tones, having a rectangular waveform and with a fundamental frequency of either 1047 or $349 \mathrm{~Hz}$. The sounds were generated by the SID chip of a Commodore 64 microcomputer, directed to a Realistic SA-150 stereo amplifier, and presented over Realistic Nova-40 headphones. Sound intensity was held constant at $70 \mathrm{~dB}$, calibrated on the A scale of a General Radio 1565-B sound level meter. Visual attributes were the capitalized, consonant-vowel bigrams HI and Lo, presented in white (Commodore color No. 1) against a gray screen background (color No. 11). Bigrams were presented on either a Taxan 220 or a Super Brain CM13L color monitor. Appearing at a distance of approximately $63.5 \mathrm{~cm}$ from the center of the monitor screen, the bigram subtended approximately $6.31^{\circ}$ of visual angle.

Each auditory attribute (high pitch, low pitch) was paired (i.e., presented simultaneously) with each visual attribute (HI, LO) to form four cross-modal stimuli (high/HI, high/LO, low/HI, low/LO). From these stimuli, we created 10 experimental tasks ( 5 involving pitch classification, 5 involving word classification) of 48 trials each. Four of these tasks were unidimensional (baseline), two involved a positive correlation of dimensions, two involved a negative correlation of dimensions, and two involved the orthogonal variation of dimensions (filtering).

Baseline: The subjects discriminated between the two attributes on one dimension (e.g., high vs. low pitch), while only a single attribute from the other dimension appeared (e.g., $\mathrm{HI}$ ).

Positively correlated dimensions: The stimulus set contained the two congruent stimuli, that is, the stimuli whose constituent values came from corresponding poles of their respective dimensions (i.e., high/HI and low/LO). The subjects classified attributes along either the pitch or the word dimension. By comparing performance in this task with baseline, we could assess whether or not the subjects benefited from the redundant variation along the nominally irrelevant dimension.

Negatively correlated dimensions: The subjects classified attributes from the two incongruent stimuli (i.e., high/Lo and low/HI), again according to either the pitch or the word dimension.

Filtering: The subjects classified all four stimuli as belonging to either two pitch categories (high vs. low) or two word categories (HI vs. LO). By comparing performance in this task with baseline, we could measure how well the subjects could ignore orthogonal variation along the irrelevant dimension.

Equal numbers of the two stimuli (baseline, correlated dimensions) or four stimuli (filtering) were included in each task.

Procedure. The subjects were tested individually in a darkened, sound-attenuated booth. The subjects performed the five pitch or five word classifications together as a set, with half of the subjects first performing pitch tasks and half first performing word tasks. Order of task within each set of five was specified by four $5 \times 5$ Latin squares. Prior to performing the five experimental tasks, the subjects performed one of the baseline tasks as practice; the particular baseline task was balanced across subjects. No practice data were analyzed.
Trials were presented randomly within each block. The subject initiated each trial by pressing the space bar of the computer keyboard. The stimulus followed $1 \mathrm{sec}$ later. Discriminations were made by pressing either a right- or left-hand key on the keyboard. Key assignment to the four stimulus attributes (i.e., high, low, HI, LO) was balanced across subjects. The subject's keypress terminated the stimulus. The time elapsed between onset of the stimulus and the subject's response was measured in milliseconds using a software timer (Price, 1979). We instructed the subjects to ignore the irrelevant attribute and to discriminate relevant attributes as quickly as possible without error. We informed the subject of incorrect responses by displaying a message on the computer's monitor. The subjects who responded slower than $800 \mathrm{msec}$ on any trial were instructed (through a screen message) to respond more quickly. Following each task, we informed the subjects of their mean reaction time (RT) and error rate. A session lasted $45 \mathrm{~min}$ on average.

\section{Results}

Overall performance. Mean RTs and proportions of errors for word and pitch judgments in the three types of tasks (baseline, correlated dimensions, and filtering) appear in Table 1. The two judgments were unequally discriminable at baseline, word judgments $(319 \mathrm{msec})$ being made $32 \mathrm{msec}$ faster than were pitch judgments (351 msec), $[F(1,19)=22.44, p<.001]$. However, as we shall see, this inequality in no way jeopardizes our interpretation of the results. The overall error rate was .05 . Speed correlated .89 with accuracy (averaged across each experimental task).

Effects of correlated and uncorrelated dimensions. An analysis of variance (ANOVA) of RTs uncovered significant Garner interference: The subjects performed the filtering tasks ( $359 \mathrm{msec}) 24 \mathrm{msec}$ slower than they performed the baseline tasks $(335 \mathrm{msec})[F(1,19)=15.39$, $p=.001]$. Garner interference was $24 \mathrm{msec}$ for both word and pitch judgments, and both effects were significant when tested alone: word $(343 \mathrm{vs} .319 \mathrm{msec})[F(1,19)=$ 9.97, $p<.01]$; pitch $(375$ vs. $351 \mathrm{msec})[F(1,19)=$ $4.78, p=.04]$.

Positively correlated dimensions produced a reliable redundancy gain (22 msec: 313 vs. $335 \mathrm{msec})[F(1,19)=$ 28.37, $p<.001]$. Negatively correlated dimensions $(333 \mathrm{msec})$ led to neither gain nor loss relative to baseline $[F(1,19)=.25$, n.s. $]$. Both the gain to positively correlated dimensions and the baseline performance to negatively correlated dimensions obtained when word and pitch judgments were analyzed separately. Moreover, none of the effects in Experiment 1 interacted with type of judg-

Table 1

Mean RTs (in milliseconds) for Judgments of Visual Words and Pitches in Baseline, Filtering, and Correlated-Dimensions Tasks (Experiment 1)

\begin{tabular}{|c|c|c|c|c|c|c|}
\hline \multirow[b]{2}{*}{ Task } & \multicolumn{2}{|c|}{ Words } & \multicolumn{2}{|c|}{ Pitches } & \multicolumn{2}{|c|}{ Overall Mean } \\
\hline & $M \mathrm{RT}$ & $\begin{array}{c}\text { Proportion } \\
\text { of Errors }\end{array}$ & $M \mathrm{RT}$ & $\begin{array}{l}\text { Proportion } \\
\text { of Errors }\end{array}$ & $M \mathrm{RT}$ & $\begin{array}{l}\text { Proportion } \\
\text { of Errors }\end{array}$ \\
\hline Baseline & 319 & .04 & 351 & .07 & 335 & .05 \\
\hline Filtering & 343 & .06 & 375 & .06 & 359 & .06 \\
\hline Positively Correlated Dimensions & 303 & .03 & 322 & .04 & 313 & .04 \\
\hline Negatively Correlated Dimensions & 315 & .03 & 350 & .06 & 333 & .05 \\
\hline Mean & 320 & .05 & 350 & .06 & 335 & .05 \\
\hline
\end{tabular}


ment, implying that even though words and pitches were mismatched in discriminability, they interacted equally with each other.

Error data were consistent with the RT data, although the effects were generally weaker. A two-way ANOVA of errors with dimension (word, pitch) and task (five levels: two baseline, two correlated, and filtering) as factors showed a main effect of dimension $[F(1,19)=8.46$, $p<.01]$, a main effect of task $[F(4,76)=2.99, p=$ .02] but no interaction $[F(4,76)=.91$, n.s.]. A NewmanKeuls test of the task effect (.05 level) revealed that it was due to the fact that significantly fewer errors were made in the positively correlated dimensions tasks (.04) than were made in either the filtering tasks $(.06)$ or the baseline tasks $(.05)$, which did not differ from each other.

Effects of congruity. The subjects responded $12 \mathrm{msec}$ faster to stimuli containing congruent attributes than to those containing incongruent attributes $[F(1,19)=18.35$, $p<.001]$. For each subject, we derived a congruity score (i.e., the difference between mean RTs to incongruent and congruent stimuli) in each of three contexts of classification: single dimension, correlated dimensions, and orthogonal dimensions. Mean congruity scores and error rates appear in Table 2 . We tested for congruity effects (i.e., congruity scores significantly greater than zero), using individual $t$ tests. Congruity effects were found for orthogonally varied dimensions $(17 \mathrm{msec})[t(19)=4.18$, $p<.001]$ and for correlated dimensions $(19 \mathrm{msec})[t(19)$ $=3.11, p<.01]$, but not for single dimension $(2 \mathrm{msec})$ $[t(19)=.83$, n.s. $]$. An ANOVA of these congruity scores revealed a significant main effect of context $[F(1,19)=$ $4.28, p=.02]$ : The congruity scores for orthogonal and correlated dimensions were significantly greater than were those for single dimension, as tested by Newman-Keuls (.05 criterion level). Congruity scores did not interact with type of judgment $[F(2,38)=.40$, n.s. $]$.

\section{Discussion}

While classifying a linguistic dimension, the subjects suffered significant Garner interference when a nonlinguistic dimension varied orthogonally; while classifying a nonlinguistic dimension, they suffered interference when a linguistic dimension varied orthogonally. To the best of our knowledge, ours is the first report of this pattern. The finding is unlike that of Wood (1975), who found an asymmetry of Garner interference: Varying his nonlinguistic dimension interfered with classification of his linguistic dimension, but varying his linguistic dimension had no effect on classifying his nonlinguistic dimension. Importantly, our symmetric interaction occurred with cross-modal dimensions whose attributes are meaningfully related to one another. It is possible, then, that the shared meaning among attributes figured prominently in creating this interaction.

In all important respects, the results obtained here with the dimensions word and pitch were identical to those reported by Melara and O'Brien (1987) with the dimensions position and pitch. First, significant Garner interference obtained with both pairs of dimensions; we assume that crosstalk was bidirectional in both cases. Second, redundancy gain was restricted to positively correlated dimensions; as before, negatively correlated dimensions produced neither gain nor loss. Third, a significant congruity effect obtained; attributes from congruent stimuli were classified faster than were attributes from incongruent stimuli. The remarkable consistency across the two studies suggests the obvious possibility that both dimensional interactions may be supported by the same cognitive mechanisms. We discuss this possibility later in detail.

\section{Two Types of Crosstalk}

Whether or not our word-pitch dimensions interact at the same level as Melara and O'Brien's position-pitch dimensions, it is clear that the pattern obtained with linguistically corresponding dimensions differs from that found with integral dimensions, such as saturation and brightness. First, with integral dimensions, both correlated tasks lead to redundancy gain; with corresponding dimensions, gain appears only when the dimensions are correlated positively. Second, attributes on corresponding dimensions, unlike integral dimensions, can be paired

Table 2

Mean RTs (in milliseconds) to Attributes from Congruent and Incongruent Stimuli for Judgments of Visual Words and Pitches in Single-Dimension, Orthogonal-, and Correlated-Dimensions Contexts (Experiment 1)

\begin{tabular}{lcccccr}
\hline & \multicolumn{2}{c}{ Congruent Stimuli } & & Incongruent Stimuli \\
\cline { 2 - 3 } \multicolumn{1}{c}{ Task Type } & $M$ RT & $\begin{array}{c}\text { Proportion } \\
\text { of Errors }\end{array}$ & $M$ RT & $\begin{array}{c}\text { Proportion } \\
\text { of Errors }\end{array}$ & $\begin{array}{r}\text { Congruity } \\
\text { Score }\end{array}$ \\
\hline Single Dimension & 319 & .04 & 319 & .05 & 0 \\
Orthogonal Dimensions & 339 & .05 & 348 & .06 & +9 \\
Correlated Dimensions & 303 & .03 & 315 & .03 & +12 \\
Weighted Mean & 316 & .04 & 323 & .05 & +7 \\
& & Pitches & & & \\
Single Dimension & 349 & .05 & 353 & .09 & +4 \\
Orthogonal Dimensions & 362 & .05 & 388 & .08 & +26 \\
Correlated Dimensions & 322 & .05 & 350 & .06 & +28 \\
Weighted Mean & 341 & .05 & 359 & .08 & +18 \\
\hline
\end{tabular}


meaningfully as congruent or incongruent; this fact is the presumed basis of the significant congruity effects that obtain with these dimensions. These two differences, together with the fact that one of our dimensions was linguistic, strongly implies that interaction between integral dimensions occurs at a level of processing different from interaction between corresponding dimensions. We suggest that the former crosstalk is bidirectional sensory/ perceptual (Figure 1, Panel A), whereas the latter is bidirectional semantic (Figure 1, Panel B).

Alternatively, perhaps the perceptual characteristics of the letters in our words interacted with perceptual characteristics of the sounds, causing sensory/perceptual crosstalk such as that found with integral dimensions. It is unclear what these perceptual characteristics might be or how they might lead to congruity effects. Nonetheless, one way to test this alternative explanation is to pair our linguistic dimension with a different nonlinguistic dimension and examine whether the same pattern of interaction obtains. We did exactly this in Experiment 2.

\section{EXPERIMENT 2}

\section{Visual Words and Position}

In Experiment 2, the words $\mathrm{HI}$ and Lo were presented either slightly above or slightly below midline on a computer screen. Thus, the dimensions to be classified (word and position) were unimodally corresponding. In this respect, the dimensions were similar to position and direction of arrows, the unimodal dimensions tested in speeded classification by Clark and Brownell (1976). However, compared with Clark and Brownell's dimensions, the correspondence between our dimensions represents a better test of our semantic-crosstalk hypothesis.

With position and direction of arrows, the locus of processing is ambiguous. For example, Wagner et al. (1981) report that 11-month-old infants appreciate the synesthetic correspondence between the direction of arrows and ascending or descending tones. Obviously, it is difficult to argue that correspondence in these preverbal infants occurred at a verbal level. Similarly, for adults, however abstract the correspondence between position and direction of arrows appears, it is still possible that the coding of these dimensions occurs at a prelinguistic stage of processing. On the other hand, it is unlikely that correspondences between our word and position attributes are made at a prelinguistic level. Thus, our dimensions provide the first clear test for Garner interference and congruity effects between unimodally corresponding dimensions having a linguistic component. Moreover, unlike Clark and Brownell (1976), we shall be able to compare directly this unimodal pair with the analogous cross-modal pair tested in Experiment 1. If the results of Experiment 2 mirror those of Experiment 1, we are in a stronger position to argue that crosstalk occurred within a semantic level of processing.

\section{Method}

Subjects. Twenty subjects ( 9 men and 11 women) were paid $\$ 5$ per hour to participate.

Stimuli, Apparatus, and Procedure. No sound equipment was used in Experiment 2; otherwise, the apparatus were identical to Experiment 1. The stimuli consisted of the words $\mathrm{HI}$ and Lo, presented either $6.76^{\circ}$ above (high position) or below (low position) midline center of the computer screen. The relatively small distance separating high from low positions reflected our efforts in pilot work to match the word and position dimensions in baseline discriminability. Other aspects of stimulus presentation, task construction, and procedure duplicated those in Experiment 1.

\section{Results}

Overall performance. RTs and error rates for word and position classifications appear in Table 3 . We succeeded in matching baseline word $(352 \mathrm{msec})$ and position ( $346 \mathrm{msec}$ ) discriminations, whose baseline RTs did not differ significantly $[F(1,19)=.36$, n.s.]. The overall error rate was .03 . The speed-accuracy correlation was .34 .

Effects of correlated and uncorrelated dimensions. Filtering tasks $(371 \mathrm{msec})$ were performed $22 \mathrm{msec}$ slower on average than were baseline tasks $(349 \mathrm{msec})$, a significant effect of Garner interference $[F(1,19)=$ $11.47, p<.01$ ]. Garner interference was $18 \mathrm{msec}$ for word judgments ( 352 vs. $370 \mathrm{msec}$ ) and $25 \mathrm{msec}$ for position judgments (346 vs. $371 \mathrm{msec}$ ); both effects were reliable $[F(1,19)=8.52, p<.01$, and $F(1,19)=8.64$, $p<.01$, respectively] and there was no interaction between task (baseline, filtering) and dimension (word, position) $[F(1,19)=1.13$, n.s. $]$.

As in Experiment 1, redundancy gain was restricted to dimensions correlated positively ( $22 \mathrm{msec}: 327$ vs. $349 \mathrm{msec})[F(1,19)=16.66, p<.001]$; negatively correlated dimensions again were classified at baseline level $(348$ vs. $349 \mathrm{msec})[F(1,19)=.01$, n.s. $]$. Each of these

Table 3

Mean RTs (in milliseconds) for Judgments of Visual Words and Positions in Baseline, Filtering, and Correlated-Dimensions Tasks (Experiment 2)

\begin{tabular}{|c|c|c|c|c|c|c|}
\hline \multirow[b]{2}{*}{ Task } & \multicolumn{2}{|c|}{ Words } & \multicolumn{2}{|c|}{ Positions } & \multicolumn{2}{|c|}{ Overall Mean } \\
\hline & $M \mathrm{RT}$ & $\begin{array}{l}\text { Proportion } \\
\text { of Errors }\end{array}$ & $M \mathrm{RT}$ & $\begin{array}{l}\text { Proportion } \\
\text { of Errors }\end{array}$ & $M \mathrm{RT}$ & $\begin{array}{l}\text { Proportion } \\
\text { of Errors }\end{array}$ \\
\hline Baseline & 352 & .03 & 346 & .04 & 349 & .04 \\
\hline Filtering & 370 & .02 & 371 & .04 & 371 & .03 \\
\hline Positively Correlated Dimensions & 332 & .01 & 322 & .02 & 327 & .01 \\
\hline Negatively Correlated Dimensions & 345 & .01 & 351 & .05 & 348 & .03 \\
\hline Mean & 350 & .02 & 348 & .04 & 349 & .03 \\
\hline
\end{tabular}


effects was replicated in separate analyses of individual dimensions, and there were no task $\times$ dimension interactions.

A two-way ANOVA of error data showed a main effect of dimension (word, position) $[F(1,19)=13.59, p<$ $.01]$ and a main effect of task (two baseline, two correlated, and filtering) $[F(4,76)=5.63, p<.001]$, but no interaction $[F(4,76)=1.98$, n.s.]. Significantly fewer errors were committed in the positively correlated task (.01) than in any other task, as tested by Newman-Keuls (.05 level). No other tasks differed in errors.

Effect of congruity. Attributes from congruent stimuli were classified $14 \mathrm{msec}$ faster than were attributes from incongruent stimuli $[F(1,19)=20.34, p<.001]$. An ANOVA and a subsequent Newman-Keuls test showed that congruity effects were significantly larger for correlated dimensions $(21 \mathrm{msec})$ than for single dimension $(6 \mathrm{msec})$, with orthogonal dimensions (14 $\mathrm{msec})$ falling between $[F(2,38)=3.30, p<.05]$. Results are summarized in Table 4. Individual $t$ tests showed that the congruity effect in each context was significantly positive [correlated dimensions, $t(19)=3.80, p=.001$; single dimension, $t(19)=2.42, p=.03$; orthogonal dimensions, $t(19)=3.02, p<.01]$. Congruity scores showed no interaction between context (single, correlated, orthogonal) and dimension (word, position) $[F(2,38)=.03$, n.s.], although congruity effects were always larger for position classifications than for word classifications.

\section{Discussion}

Experiment 2 replicated Experiment 1. In speeded classification of unimodally corresponding word and position, as in classification of cross-modally corresponding word and pitch, the subjects experienced Garner interference, redundancy gain to positively correlated dimensions, baseline performance to negatively correlated dimensions, and significant effects of congruity. Results from the two experiments matched almost perfectly, except that in Experiment 2 we found a significant congruity effect in the context of baseline tasks (we discuss this finding in Ex- periment 3 ). ${ }^{1}$ These results support the view that number of modalities is incidental to effects of correspondence and interaction. At least in the case of the dimensions tested thus far, unimodally and cross-modally corresponding dimensions produce equivalent patterns of interaction, both in form and in magnitude. Together, results from the two experiments fit well our view that correspondence interactions, at least as they occur between these dimensions, have a bidirectional semantic basis.

\section{EXPERIMENT 3}

\section{Spoken Words and Position}

In Experiments 1 and 2, we tested speeded classification when a linguistic dimension was presented visually. In Experiment 3, we asked whether these results are special to the visual modality, or whether correspondence interactions still occur when linguistic information is transmitted through the auditory modality. The dimensions used here were (1) the aurally presented words "high" and "low" and (2) the vertical position in space from which those words were presented. One striking difference between aurally and visually presented words concerns the time course of linguistic/semantic processing. Aurally presented information extends temporally and so entails an accumulation of partial information across time. Visually presented information, on the other hand, is available to the perceiver more immediately. Perhaps position interacts with a linguistic dimension when extension through time is minimal, as in the case of visually presented words, but does not interact (or interacts asymmetrically) in cases where the temporal factor is critical, as it was here. This result might be expected all the more given the special status some have claimed for the perceptual processing of position information (e.g., Jackson, 1953; Nissen, 1985; Pick, Warren, \& Hay, 1969; Von Wright, 1970). Of course, it is important to ensure that failures of interaction are due to the linguistic dimension itself and not to the fact that discriminating aurally presented words is more difficult than discriminating the

Table 4

Mean RTs (in milliseconds) to Attributes from Congruent and Incongruent Stimuli for Judgments of Visual Words and Positions in Single-Dimension, Orthogonal-, and Correlated-Dimensions Contexts (Experiment 2)

\begin{tabular}{lcccccc}
\hline & \multicolumn{2}{c}{ Congruent Stimuli } & & Incongruent Stimuli \\
\cline { 2 - 3 } \multicolumn{1}{c}{ Task Type } & $M$ RT & $\begin{array}{c}\text { Proportion } \\
\text { of Errors }\end{array}$ & $M$ RT & $\begin{array}{c}\text { Proportion } \\
\text { of Errors }\end{array}$ & $\begin{array}{c}\text { Congruity } \\
\text { Score }\end{array}$ \\
\hline Single Dimension & 353 & .03 & 352 & .03 & -1 \\
Orthogonal Dimensions & 368 & .01 & 372 & .03 & +4 \\
Correlated Dimensions & 332 & .01 & 345 & .01 & +13 \\
Weighted Mean & 348 & .02 & 353 & .02 & +5 \\
& & Positions & & & \\
Single Dimension & 339 & .03 & 352 & .05 & +13 \\
Orthogonal Dimensions & 360 & .03 & 383 & .05 & +23 \\
Correlated Dimensions & 322 & .02 & 351 & .05 & +29 \\
Weighted Mean & 336 & .03 & 358 & .05 & +22 \\
\hline
\end{tabular}


position of the words. To provide an adequate empirical test, we therefore collected extensive pilot data at various baseline levels and, accordingly, chose values on the linguistic dimension that were at least as discriminable as those on the position dimension.

\section{Method}

Subjects. Twenty subjects ( 10 men and 10 women) were paid $\$ 5$ to participate.

Stimuli, Apparatus, and Procedure. Spoken stimuli were synthesized by the sound chip of a Motorola 68000 microprocessor, installed in an Amiga 500 microcomputer. The voice had a fundamental frequency of $110 \mathrm{~Hz}$, a waveform sampling frequency of $22 \mathrm{kHz}$, and a speaking rate of 300 words per minute. These parameters created a voice similar to that of an adult male saying a monosyllabic word at normal speed. The words were "high" (ARPABET phoneme code $=/$ HAYl.) or "low" (ARPABET code = LOW 1.). The auditory signals were directed to a Realistic SA150 amplifier and presented over one of two Sonic SP-500 speakers. The speakers were positioned at a distance of approximately $66 \mathrm{~cm}$ from and directly facing the seated subject. The low-positioned speaker was placed on the floor, approximately $89 \mathrm{~cm}$ below a point midway between the subject's ears. The high-positioned speaker was suspended approximately $38 \mathrm{~cm}$ above the subject's head. The subjects made either voice classifications or position classifications in the full speeded-classification design, exactly as in the previous experiments. Responses were made by pressing the right or left key of a dual-key Amiga mouse. RTs were measured in milliseconds by the $716-\mathrm{kHz}$ clock in the Complex Interface Adapter $8520 \mathrm{~A}$ chip of the Motorola 68000 (Wright, 1986). We chose this hardware timer rather than a version of the machine-language timer used earlier because the "multitasking" capabilities of the 68000 microprocessor corrupt the accuracy of software measurements (see Wright, 1986). All other aspects of Experiment 3 duplicated Experiments 1 and 2 .

\section{Results}

Overall performance. A summary of performance in each task appears in Table 5. The overall error rate was .02 . Speed correlated .94 with accuracy. Baseline word discriminations $(520 \mathrm{msec})$ were made $31 \mathrm{msec}$ faster than were baseline position discriminations $(551 \mathrm{msec})$ $[F(1,19)=4.58, p<.05]$. Thus, these data meet our requirement that words be at least as discriminable as positions.

Effects of correlated and uncorrelated dimensions. Orthogonal variation of one dimension caused, on average, $40 \mathrm{msec}$ of Garner interference in classifying the other dimension (575 vs. $535 \mathrm{msec})[F(1,19)=13.23$, $p<.01]$. Significant Garner interference obtained for word classifications ( 568 vs. $520 \mathrm{msec}$ ) and position classifications (582 vs. $551 \mathrm{msec}$ ) when analyzed separately $[F(1,19)=11.64, p<.01$, and $F(1,19)=5.91, p<$ .05 . respectively]. There were no interactions between type of task (baseline, filtering) and dimension (word, position) $[F(1,19)=1.28$, n.s. $]$.

Attributes from positively correlated dimensions $(515 \mathrm{msec})$ were classified $20 \mathrm{msec}$ faster than baseline $[F(1,19)=7.39, p=.01]$. Both word classification (507 vs. $520 \mathrm{msec}$ ) and position classification (522 vs, $551 \mathrm{msec}$ ) showed redundancy gain when analyzed separately $[F(1,19)=4.59, p=.05$, and $F(1,19)=4.57$, $p=.05$, respectively]. Attributes from negatively correlated dimensions $(530 \mathrm{msec})$ were classified $5 \mathrm{msec}$ faster than baseline, a nonsignificant difference $[F(1,19)$ $=.67$, n.s. J. However, with negatively correlated dimensions, the interaction between task (negatively correlated, baseline) and dimension (word, position) was significant $[F(1,19)=10.05, p<.01]$. This interaction was based on the following pattern: Word judgments were made a nonsignificant $15 \mathrm{msec}$ slower than baseline when positions were correlated negatively $[F(1,19)=2.10$, n.s. $]$, whereas position judgments were made a significant 26 msec faster than baseline when words were correlated negatively $[F(1,19)=9.67, p<.01]$.

Error data were consistent with RT data. A two-way ANOVA of errors found a significant effect of dimension (word, position) $[F(1,19)=8.52, p<.01]$, a significant effect of task (5 levels) $[F(4,76)=7.32, p<$ $.001]$, but no interaction between dimension and task $[F(4,76)=1.98$, n.s. $]$. Post hoc analysis of the task effect indicated that positively correlated tasks (.01) led to fewer errors than did one of the baseline tasks (.03) and that the filtering tasks (.04) produced more errors than did any other task.

Effects of congruity. A summary of congruity scores appears in Table 6 . Attributes from congruent stimuli $(530 \mathrm{msec})$ were classified $17 \mathrm{msec}$ faster than were attributes from incongruent stimuli $(547 \mathrm{msec})[F(1,19)=$ $18.99, p<.001]$. In each of three contexts, congruity effects were significantly greater than zero [orthogonal dimensions ( $33 \mathrm{msec}$ ), $t(19)=3.51, p<.01$; correlated dimensions $(16 \mathrm{msec}), t(19)=2.86, p=.01$; single dimension ( $11 \mathrm{msec}), t(19)=2.51, p=.02$ ]. However, context interacted with classification dimension $[F(2,38)$ $=3.62, p=.04]$. In the context of correlated dimen-

Table 5

Mean RTs (in milliseconds) for Judgments of Spoken Words and Positions in Baseline, Filtering, and Correlated-Dimensions Tasks (Experiment 3)

\begin{tabular}{|c|c|c|c|c|c|c|}
\hline \multirow[b]{2}{*}{ Task } & \multicolumn{2}{|c|}{ Words } & \multicolumn{2}{|c|}{ Positions } & \multicolumn{2}{|c|}{ Overall Mean } \\
\hline & $M \mathrm{RT}$ & $\begin{array}{c}\text { Proportion } \\
\text { of Errors }\end{array}$ & $M \mathrm{RT}$ & $\begin{array}{c}\text { Proportion } \\
\text { of Errors }\end{array}$ & $M \mathrm{RT}$ & $\begin{array}{l}\text { Proportion } \\
\text { of Errors }\end{array}$ \\
\hline Baseline & 520 & .02 & 551 & .03 & 535 & .02 \\
\hline Filtering & 568 & .03 & 582 & .04 & 575 & .04 \\
\hline Positively Correlated Dimensions & 507 & .01 & 522 & .01 & 515 & .01 \\
\hline Negatively Correlated Dimensions & 535 & .02 & 525 & .02 & 530 & .02 \\
\hline Mean & 533 & .02 & 545 & .03 & 539 & .02 \\
\hline
\end{tabular}


Table 6

Mean RTs (in milliseconds) to Attributes from Congruent and Incongruent Stimuli for Judgments of Spoken Words and Positions in Single-Dimension, Orthogonal-, and Correlated-Dimensions Contexts (Experiment 3)

\begin{tabular}{lcccccr}
\hline & \multicolumn{2}{c}{ Congruent Stimuli } & & Incongruent Stimuli & \\
\cline { 2 - 3 } \multicolumn{1}{c}{ Task Type } & $M$ RT & $\begin{array}{c}\text { Proportion } \\
\text { of Errors }\end{array}$ & & $M$ RT & $\begin{array}{c}\text { Proportion } \\
\text { of Errors }\end{array}$ & $\begin{array}{c}\text { Congruity } \\
\text { Score }\end{array}$ \\
\hline Single Dimension & 515 & .02 & 523 & .02 & +8 \\
Orthogonal Dimensions & 556 & .02 & 580 & .04 & +24 \\
Correlated Dimensions & 507 & .02 & 535 & .02 & +28 \\
Weighted Mean & 520 & .02 & 539 & .02 & +19 \\
& & Positions & & & \\
Single Dimension & 544 & .03 & 558 & .04 & +14 \\
Orthogonal Dimensions & 561 & .03 & 603 & .06 & +42 \\
Correlated Dimensions & 522 & .01 & 525 & .02 & +3 \\
Weighted Mean & 539 & .02 & 554 & .04 & +15 \\
\hline
\end{tabular}

sions, a congruity effect appeared only with word judgments (28 msec) $[t(19)=2.89, p<.01]$, whereas in the context of single dimension, a congruity effect appeared only with position judgments $(14 \mathrm{msec})[t(19)=2.99$, $p<.01]$. The magnitude of congruity effect differed across the three contexts $[F(2,38)=3.56, p=.04]$, with orthogonal dimensions producing the largest effect and single dimension the smallest effect.

\section{Discussion}

Experiment 3 replicated the main features of the earlier experiments but also included one interesting difference. We replicated the Garner interference effects obtained in Experiments 1 and 2: The subjects were appreciably worse at classifying along one dimension if the other dimension varied orthogonally. We also replicated our earlier findings of cross-dimensional correspondence. First, we found substantial redundancy gain when attributes matched synesthetically, that is, when dimensions correlated positively. Second, we found substantial effects of congruity, especially when dimensions were varied orthogonally. This set of results indicates that the interactions between a linguistic and a nonlinguistic dimension obtained in Experiments 1 and 2 did not depend on visual presentation of linguistic information. Apparently, even the temporally extended dimension of speech can affect processing of position information if discrimination of the speech sounds matches roughly the discrimination of positions.

One result obtained here was unlike that obtained in earlier experiments: At least with position judgments, negatively correlated dimensions produced a sizable redundancy gain. This result is perplexing because it implies that the coding of attributes as congruent or incongruent was unimportant in a task in which stimuli were always incongruent. It is clear that the subjects were sensitive to these correspondences when making position judgments; in the context of both filtering and baseline position classifications, the subjects displayed marked congruity effects. Moreover, this finding cannot be due to characteristics of position discrimination per se, because in other experiments involving either an irrelevant linguistic dimension (Experiment 2) or an irrelevant nonlinguistic dimension (Melara \& O'Brien, 1987), position judgments were at baseline level when the dimensions correlated negatively. Therefore, we regard the present finding as anomalous.

Another interesting finding of Experiment 3 was a reliable ( $11 \mathrm{msec})$ congruity effect in the baseline judgments. A similar effect appeared in Experiment 2, but not in Experiment 1 nor in any of Melara and O'Brien's (1987) experiments with position and pitch. Melara and O'Brien (1987) agreed with the explanation suggested by Clark and Brownell (1976), namely, that the absence of congruity effects in baseline tasks reflected the absence of a standard of comparison when the irrelevant dimension was held constant. In other words, Clark and Brownell argued that values on the position and pitch dimensions were coded relatively, not absolutely; when an irrelevant dimension was held constant, the dimension itself collapsed and hence could not influence processing of the relevant dimension.

If this logic is applied to the present experiments, it suggests that attributes on our dimensions were coded at least partly in an absolute fashion. Although this reasoning is implausible in the case of our nonlinguistic dimensions, which were the same as the dimensions tested by Melara and O'Brien, it is plausible in the case of our linguistic dimensions. Assuming that linguistic dimensions are coded absolutely, this explanation is consistent with the results of both Experiments 2 and 3: In the baseline condition of both experiments, the linguistic dimension caused a congruity effect in judgments of the nonlinguistic dimension (Experiment $2=13 \mathrm{msec}, t(19)=3.47, p<.01$; Experiment $2=14 \mathrm{msec}, t(19)=2.99, p<.01$ ], but the nonlinguistic dimension did not significantly influence judgments of the linguistic dimension [Experiment $2=$ $-1 \mathrm{msec}, t(19)=.43$, n.s.; Experiment $3=8 \mathrm{msec}$, $t(19)=1.44$, n.s.; see Tables 4 and 6]. Thus, Experiments 2 and 3 support the hypothesis that absolute coding is needed to produce congruity when the irrelevant dimension is held constant. At present, we are unable to 
explain why the baseline congruity effect that obtained in these experiments was absent in Experiment 1, in which a linguistic dimension was also used. Perhaps the hypothesis of absolute coding only partially explains the presence of baseline congruity effects.

\section{EXPERIMENT 4}

\section{Spoken Words and Pitch}

Experiment 4 represents the auditory analogue of Experiment 2. In Experiment 2, we tested for an interaction between a visual linguistic dimension (visually presented words) and a visual nonlinguistic dimension (the vertical position of those words). In Experiment 4, we tested for an interaction between an auditory linguistic dimension (the words "high" and "low" presented aurally) and an auditory nonlinguistic dimension (the pitch of those words). We attempted to make these speech sounds as realistic as possible. Hence, our high-pitched voice was recognized easily as a young boy's, whereas the low-pitched voice was recognized easily as a mature man's. The two pitches differed on two physical dimensions, fundamental frequency and sampling frequency. Thus, although for convenience we consider this a dimension of pitch, the two levels on this dimension may differ more qualitatively, that is, may differ more in timbre, than they would had only fundamental frequency varied. This factor may need to be considered when interpreting the results.

\section{Method}

Subjects. Twenty subjects ( 11 men and 9 women) were paid $\$ 5$ per hour to participate.

Stimuli, Apparatus, and Procedure. The boy's voice was created using the following parameters: fundamental frequency = $280 \mathrm{~Hz}$, sampling frequency $=28 \mathrm{kHz}$, ARPABET code for "high" = /HAY2, ARPABET code for "low" = LOW4. . The man's voice was created with the parameters used in Experiment 3. Experimental tasks were defined from these four attributes (i.e., boy, man, "high," "low"), as in previous experiments. Apparatus and procedure duplicated those used in Experiment 3.

\section{Results}

Overall performance. Table 7 contains a summary of results. The overall error rate was low (.02). The speed-accuracy correlation was .93. Word ("high," “low") discrimination (499 msec) and pitch (boy, man) discrimination $(513 \mathrm{msec})$ did not differ significantly $[F(1,19)=3.26, p=.09]$.

Effects of correlated and uncorrelated dimensions. As shown in Table 7, Experiment 4 produced substantial Garner interference. The subjects classified attributes $82 \mathrm{msec}$ slower when dimensions varied orthogonally $(588 \mathrm{msec})$ compared with baseline $(506 \mathrm{msec})$ $[F(1,19)=100.51, p<.001]$. Garner interference was equal for each judgment analyzed separately: word judgments (82 msec: 581 vs. $499 \mathrm{msec})[F(1,19)=62.58$, $p<.001$ ]; pitch judgments ( $81 \mathrm{msec}: 594$ vs. $513 \mathrm{msec}$ ) $[F(1,19)=49.56, p<.001]$.

Positively correlated dimensions ( $495 \mathrm{msec}$ ) were classified significantly faster than were negatively correlated dimensions $[F(1,19)=11.12, p<.01]$. However, positively correlated dimensions were not faster than baseline overall $[F(1,19)=2.31$, n.s. $]$, although pitch judgments did show a slight redundancy gain (18 msec: 495 vs. $513 \mathrm{msec})[F(1,19)=4.29, p=.05]$. Negatively correlated dimensions, on the other hand, showed a slight redundancy loss $[F(1,19)=4.02, p=.06]$. The redundancy loss was restricted largely to word judgments ( 518 vs. $499 \mathrm{msec})[F(1,19)=7.19, p=.01]$. There were no significant interactions in Experiment 4.

As in the previous experiments, the error data were consistent with, but weaker than, the RT data. A two-way ANOVA of errors showed no effect of dimension $[F(1,19)$ $=2.79$, n.s. $]$, a significant effect of task $[F(4,76)=$ $15.90, p<.001]$, and no dimension $\times$ task interaction $[F(4,76)=1.78$, n.s. $]$. A Newman-Keuls test revealed that the task effect was due to the fact that the subjects made significantly more errors in the filtering tasks (.04) than in each of the other four tasks.

Effects of congruity. A summary of congruity effects appears in Table 8 . Attributes from congruent stimuli were classified $19 \mathrm{msec}$ faster on average than were attributes from incongruent stimuli $[F(1,19)=23.67, p<$ $.001]$. Congruity scores did not differ by context (baseline, filtering, correlated dimensions) $[F(1,19)=1.52$, n.s.], and there was no interaction between context and dimension (word, pitch) $[F(2,38)=2.30$, n.s. $]$. Individual $t$ tests showed that congruity effects with orthogonally varied dimensions ( $27 \mathrm{msec}$ ) and with correlated dimensions $(25 \mathrm{msec})$ were significant $[t(19)=3.30, p<.01$,

Table 7

Mean RTs (in milliseconds) for Judgments of Spoken Words and Pitches in Baseline, Filtering, and Correlated-Dimensions Tasks (Experiment 4)

\begin{tabular}{|c|c|c|c|c|c|c|}
\hline \multirow[b]{2}{*}{ Task } & \multicolumn{2}{|c|}{ Words } & \multicolumn{2}{|c|}{ Pitches } & \multicolumn{2}{|c|}{ Overall Mean } \\
\hline & $M \mathrm{RT}$ & $\begin{array}{c}\text { Proportion } \\
\text { of Errors }\end{array}$ & $M \mathrm{RT}$ & $\begin{array}{c}\text { Proportion } \\
\text { of Errors }\end{array}$ & $M \mathrm{RT}$ & $\begin{array}{c}\text { Proportion } \\
\text { of Errors }\end{array}$ \\
\hline Baseline & 499 & .02 & 513 & .02 & 506 & .02 \\
\hline Filtering & 581 & .03 & 594 & .05 & 588 & .04 \\
\hline Positively Correlated Dimensions & 495 & 01 & 495 & .01 & 495 & .01 \\
\hline Negatively Correlated Dimensions & 518 & .01 & 522 & .02 & 520 & .01 \\
\hline Mean & 523 & .02 & $53 !$ & .02 & 527 & .02 \\
\hline
\end{tabular}


Table 8

Mean RTs (in milliseconds) to Attributes from Congruent

and Incongruent Stimuli for Judgments of Spoken Words

and Pitches in Single-Dimension, Orthogonal-, and

Correlated-Dimensions Contexts (Experiment 4)

\begin{tabular}{lcccccr}
\hline & \multicolumn{2}{c}{ Congruent Stimuli } & & \multicolumn{2}{c}{ Incongruent Stimuli } \\
\cline { 2 - 3 } \multicolumn{1}{c}{ Task Type } & $M$ RT & $\begin{array}{c}\text { Proportion } \\
\text { of Errors }\end{array}$ & & $M$ RT & $\begin{array}{c}\text { Proportion } \\
\text { of Errors }\end{array}$ & $\begin{array}{c}\text { Congruity } \\
\text { Score }\end{array}$ \\
\hline Single Dimension & 495 & .02 & 504 & .02 & +9 \\
Orthogonal Dimensions & 573 & .03 & 588 & .03 & +15 \\
Correlated Dimensions & 495 & .01 & 518 & .01 & +23 \\
Weighted Mean & 511 & .02 & 526 & .02 & +15 \\
& & Pitches & & & \\
Single Dimension & 507 & .01 & 519 & .03 & +12 \\
Orthogonal Dimensions & 575 & .04 & 614 & .07 & +39 \\
Correlated Dimensions & 495 & .01 & 522 & .02 & +27 \\
Weighted Mean & 516 & .02 & 539 & .03 & +23 \\
\hline
\end{tabular}

and $t(19)=3.34, p<.01$, respectively], but the congruity effect to single dimension $(11 \mathrm{msec})$ was only marginally significant $[t(19)=1.93, p=.07]$.

\section{Discussion}

The pattern of interaction obtained in Experiment 4 differed slightly from that found in the previous experiments. Orthogonally varied dimensions interfered much more than before, but positively correlated dimensions facilitated much less. In addition, there was some tendency for variation on dimensions correlated negatively to produce a loss in classification efficiency. Finally, in all three contexts of classification (baseline, correlated dimensions, and filtering), effects of congruity emerged.

What accounts for these differences? One explanation implicates our nonlinguistic dimension. Compared with nonlinguistic dimensions used in the earlier experiments (i.e., pitch in Experiment 1 and vertical position in Experiments 2 and 3), the two values on the pitch dimension used in Experiment 4 differed in a truly qualitative sense. All of our subjects identified high pitch clearly as a boy's voice and low pitch as a man's voice. Thus, unlike in the previous experiments, the subjects in Experiment 4 perhaps coded these nonlinguistic attributes in an absolute, rather than a relative, fashion.

Absolute coding could affect performance in each classification condition (baseline, correlated, and orthogonal). With orthogonal variation, absolute coding may have exacerbated the contextual change in the relevant dimension wrought by the presence of the irrelevant attribute. We have argued elsewhere (Melara \& Marks, 1990b, 1990c) that greater contextual change means greater intraclass variation, which would lead to larger amounts of Garner interference. In the baseline condition, absolute coding of the irrelevant attribute could establish a basis for coding (on each trial) correspondence/noncorrespondence with the relevant attribute; as we suggested earlier, this might explain why a congruity effect obtained in this condition. More generally, processing of correspondence/ noncorrespondence may be more salient when two qualitative dimensions are involved, which might explain why performance suffered when dimensions were correlated negatively. Of course, this account does not explain why gain from positively correlated dimensions was minimal. Moreover, as we mentioned earlier, the hypothesis of absolute coding may, at best, be only a partial account of baseline congruity effects. We must therefore await a more complete explanation of the differences we found among experiments.

More importantly, we emphasize that differences among these and the previous results are small relative to the strong commonalities evident across experiments. We have shown again that a linguistic and a nonlinguistic dimension can interact symmetrically in speeded classification and that subjects are affected greatly by whether two attributes correspond. Thus, Experiment 4 represents our fourth demonstration of a correspondence interaction that seems to be explained best as bidirectional semantic crosstalk. When considered collectively, these four experiments provide cogent support for our hypothesis of semantic crosstalk.

\section{EXPERIMENT 5}

\section{Minimizing Linguistic Bias}

In each of the previous experiments, the subjects classified a linguistic dimension for half of the trials and a nonlinguistic dimension for half of the trials. And, for half of the subjects, nonlinguistic classification was performed subsequent to linguistic classification. Perhaps being exposed and/or responding to the linguistic dimension caused a bias in these subjects to use the linguistic labels when coding the nonlinguistic dimension. If so, then it would imply that the Garner interference and congruity effects found in the nonlinguistic dimension were established artifactually by our procedure.

In Experiment 5, we minimized possible bias by testing only nonlinguistic classification. The subjects were 
tested under a deadline procedure (to discourage linguistic coding) across 15 blocks of trials, alternating between baseline and filtering tasks. In this way, we could gauge (1) whether the subjects still displayed Garner interference and congruity effects even though they had no direct involvement with the linguistic dimension and (2) how stable these effects were as a function of continued involvement with the nonlinguistic dimension.

\section{Method}

Subjects. Twelve undergraduates from Purdue University $(8$ males and 4 females) participated as subjects in partial fulfillment of a course requirement.

Stimuli, Apparatus, and Procedure. Stimuli and apparatus were identical to those used in Experiment 4. All subjects practiced pitch classification in one of the two baseline tasks: For half of the subjects, the spoken word was always "low"; for the other half, the word was "high." The subjects then alternated between the baseline task and the pitch-filtering task (half of the subjects began with the filtering task), until they performed 15 consecutive blocks of paired tasks. The subjects were warned that their decision on each trial must be made within $1 \mathrm{sec}$ of stimulus presentation. Any trial with a latency greater than $1 \mathrm{sec}$ was re-presented later in that task. All other aspects replicated the previous experiments. Experiment 5 lasted approximately $1.75 \mathrm{~h}$.

\section{Results}

A summary of mean RTs in baseline and filtering tasks for each block of trials is depicted in Panel A of Figure 2; mean RTs to congruent and incongruent stimuli is depicted in Panel B of Figure 2. The overall error rate was .03; speed correlated .80 with accuracy (averaged across tasks and blocks).

The filtering tasks $(549 \mathrm{msec})$ were performed $36 \mathrm{msec}$ slower on average than were the baseline tasks $(513 \mathrm{msec})$, a significant effect of Garner interference $[F(1,11)=25.12, p<.001]$. There was no effect of block $[F(14,154)=1.17$, n.s. $]$ and no task $\times$ block interaction $[F(14,154)=.86$, n.s. $]$. These results were replicated in an ANOVA of error data. Significantly more er- rors were made in the filtering tasks (.04) than in the baseline tasks $(.02)[F(1,11)=19.00, p<.01]$. As with RTs, there was no significant effect of block $[F(14,154)$ $=1.68$, n.s. $]$ and no task $\times$ block interaction $[F(14,154)$ $=.85$, n.s.].

Attributes from congruent stimuli $(537 \mathrm{msec})$ were classified $24 \mathrm{msec}$ faster than were attributes from incongruent stimuli ( $561 \mathrm{msec}$ ), a significant effect of congruity $[F(1,11)=53.78, p<.001]$. Again, there was no effect of block $[F(14,154)=1.30$, n.s. $]$ and no interaction between congruity and block $[F(14,154)=1.18$, n.s. $]$.

\section{Discussion}

Results from Experiment 5 were straightforward and telling. Even in the absence of direct involvement with the linguistic dimension, the subjects still displayed substantial Garner interference and congruity effects. These effects were large from the first block of trials and remained relatively constant across 15 blocks of trials. These results suggest that the phenomenon under study is a powerful and robust one and that it is probably not due to an artifact of our particular procedure. We thus regard these results as supporting our hypothesis that correspondence interaction with these dimensions represents crosstalk at the semantic level of processing and does not result from labeling bias (because the subjects were never required to attend to the linguistic dimension) or response competition (because the subjects were never required to respond to the irrelevant dimension).

\section{EXPERIMENT 6}

\section{Classification of Stroop Dimensions}

The linguistic-nonlinguistic pairs of dimensions tested in these experiments share several features with the traditional Stroop dimensions, colors and color names. First, like our corresponding dimensions, Stroop dimensions entail a match or mismatch between attributes from one
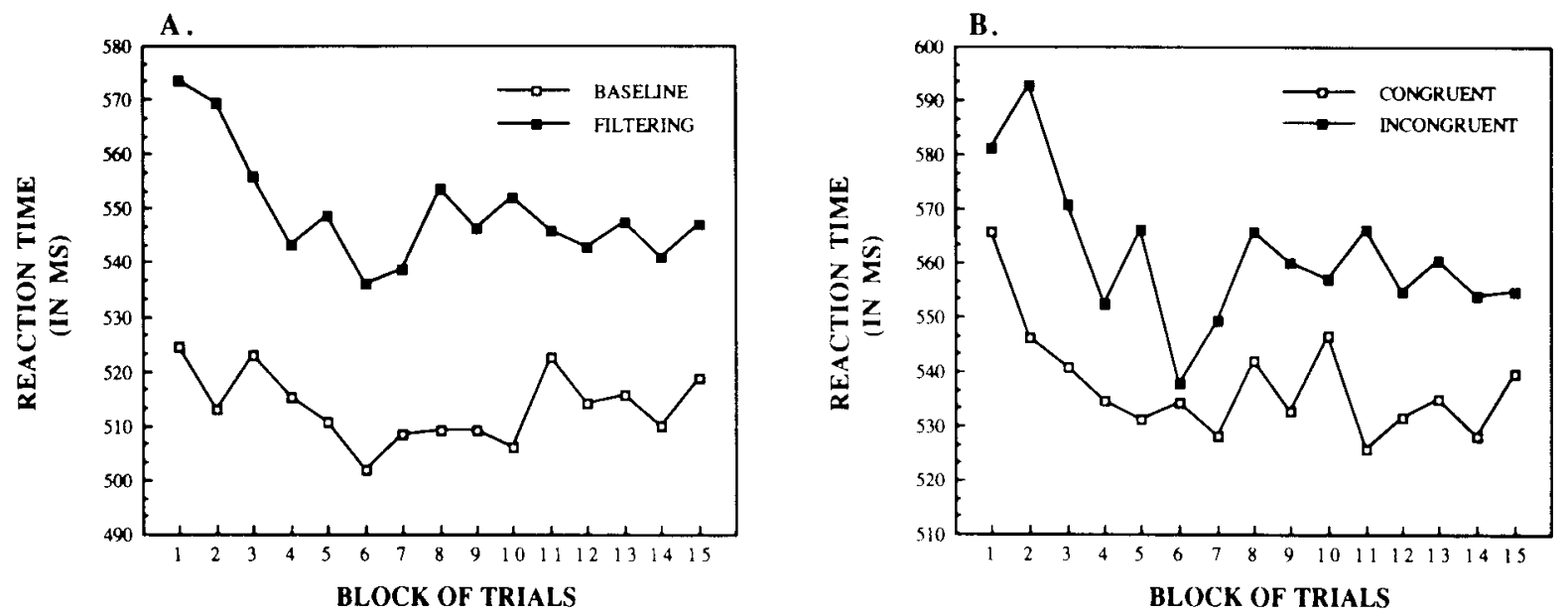

Figure 2. Mean RTs (in milliseconds) in each of 15 blocks of trials to classify pitches of the spoken words "high" and "low." Panel A: Mean RTs in the baseline and filtering tasks. Panel B: Mean RTs to classify attributes from congruent and incongruent stimuli. 
dimension (e.g., the words WHITE or BLACK) and attributes from the other dimension (e.g., the colors white or black), where one dimension is linguistic and the other nonlinguistic. Second, like our dimensions, under certain conditions (see Dyer, 1973) Stroop dimensions show congruity effects, with subjects responding faster when attributes match than when they mismatch. Moreover, under certain conditions (see Virzi \& Egeth, 1985), the congruity effect is larger for the nonlinguistic dimension (colors) than for the linguistic dimension (color names). Similarly, across our first four experiments, congruity effects were $7 \mathrm{msec}$ larger for the nonlinguistic dimension $(19 \mathrm{msec})$ than for the linguistic dimension $(12 \mathrm{msec})$ $[F(1,76)=6.77, p=.01]$. These commonalities imply that corresponding dimensions are processed like Stroop dimensions (cf. Logan, 1980).

On the other hand, corresponding dimensions differ from Stroop dimensions in several respects. First, congruity effects obtained with Stroop dimensions seem based in slower performance (interference) when attributes mismatch (see Dyer, 1973; Seymour, 1974), whereas congruity effects obtained with corresponding dimensions depend substantially on faster performance (facilitation) when attributes match (Melara, 1989a; Melara \& O'Brien, 1990). Second, unlike congruity effects with corresponding dimensions, the appearance of Stroop congruity effects depends heavily on the mode of decision responding (e.g., Klein, 1964; McClain, 1983; Pritchatt, 1968; Treisman \& Fearnley, 1969; Virzi \& Egeth, 1985). That is, Stroop effects are based largely on the requirement of a linguistic response mode (i.e., naming) to the nonlinguistic dimension (i.e., colors). Virzi and Egeth (1985), for example, showed that Stroop effects are eliminated if the response mode to the colors is nonlinguistic (e.g., matching colors of sorting bins). This dependence on response mode seems not to characterize congruity effects found with corresponding dimensions (i.e., the response mode is typically conflict-free keypressing), suggesting that processing of Stroop dimensions may differ qualitatively from the processing of corresponding dimensions.

Do Stroop dimensions interact in speeded classification? To the best of our knowledge, colors and color names have never been tested in Garner's paradigm. In Experiment 6, we tested the traditional Stroop dimensions in the procedure used in Experiment 5: The subjects classified the nonlinguistic dimension (colors) across 15 blocks of trials, alternating between baseline and filtering tasks. The response mode entailed keystrokes, as in previous experiments. Do Stroop dimensions show Garner interference and/or effects of congruity? Are these effects stable over the course of trials?

\section{Method}

Subjects. Twelve Purdue University undergraduates ( 7 men and 5 women) participated as subjects in partial fulfillment of a course requirement.

Stimuli, Apparatus, and Procedure. Stimuli were the words WHITE or BLACK generated by an Amiga 500 microcomputer and displayed on an Amiga 1084S color monitor in either white or black color against a gray screen background (see Dyer, 1971). The subjects sat at a distance of approximately $70 \mathrm{~cm}$; stimuli subtended $8.53^{\circ}$ of visual angle. Following practice, the subjects performed 15 blocks of color classification trials, alternating in each block between baseline and filtering tasks. All aspects of the procedure were identical to Experiment 5.

\section{Results}

Mean RTs in the baseline and the filtering tasks for each block of trials appear in Panel A of Figure 3; mean RTs to attributes from congruent and incongruent stimuli appear in Panel B of Figure 3. The overall error rate was .03 ; speed correlated .51 with accuracy.

The filtering tasks $(337 \mathrm{msec})$ were performed only slightly $(6 \mathrm{msec})$, but reliably, slower on average than were the baseline tasks $(331 \mathrm{msec})[F(1,11)=8.62, p=$ .01 ]. As can be seen in Panel A of Figure 3, Garner interference was substantial in the first block of trials
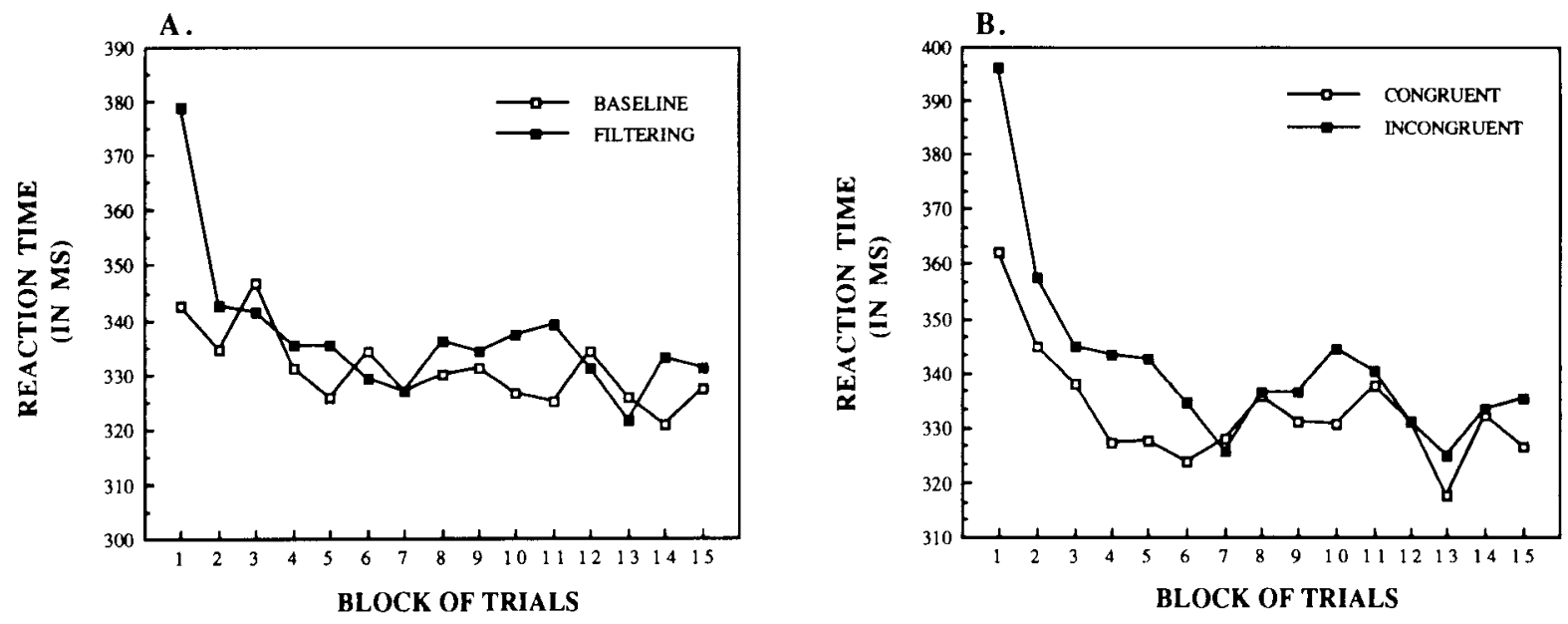

Figure 3. Mean RTs (in milliseconds) in each of 15 blocks of trials to classify colors of the visual words white and BLAck. Panel A: Mean RTs in the baseline and filtering tasks. Panel B: Mean RTs to classify attributes from congruent and incongruent stimuli. 
(37 msec), but it was erratic in subsequent blocks. There was a significant effect of block $[F(14,154)=1.79, p=$ $.04]$, because RTs in the first block were significantly slower than those in any other blocks (as tested by NewmanKeuls). The task $\times$ block interaction was not reliable $[F(14,154)=1.60, p=.09]$. An ANOVA of error data showed no effect of task $[F(1,11)=1.65$, n.s. $]$, no effect of block $[F(14,154)=1.21$, n.s. $]$, and no interaction between task and block $[F(14,154)=1.30$, n.s. $]$

Attributes from congruent stimuli $(333 \mathrm{msec})$ were classified $9 \mathrm{msec}$ faster overall than were attributes from incongruent stimuli $(342 \mathrm{msec})[F(1,11)=10.23, p<$ .01]. RTs in the first block of trials were significantly slower than the RTs in all but the second block of trials $[F(14,154)=2.76, p=.001]$, as tested by NewmanKeuls. There was a significant interaction between congruity and block $[F(14,154)=1.81, p=.04]$. As can be seen in Panel B of Figure 3, this interaction is attributable to the fact that congruity effects averaged $16 \mathrm{msec}$ in the first six blocks of trials, but only $4 \mathrm{msec}$ thereafter.

\section{Discussion}

Processing of Stroop dimensions appears to differ fundamentally from the processing of corresponding dimensions, a conclusion that is appreciated readily by comparing Figure 2 with Figure 3. With corresponding words and pitch (Figure 2), both Garner interference (Panel A) and congruity effects (Panel B) were large and remained relatively constant across blocks of trials (see also Melara, 1989a). In contrast, with Stroop dimensions (Figure 3), Garner interference (Panel A) was small overall, so small as to suggest dimensional separability. Congruity effects (Panel B) were also weak and appeared to diminish across blocks of trials.

Our use of a neutral response mode (keypressing), which we implemented to provide a clear basis for comparison with the earlier experiments, is one possible determinant of the small Stroop effect we obtained (see, e.g., Virzi \& Egeth, 1985). We stress, however, that the Stroop dimensions did show substantial Garner interference and effects of congruity in the first block of trials (37 and $34 \mathrm{msec}$, respectively). Effects in the first block of trials differed significantly (as tested by linear contrast in an ANOVA) from the average Garner interference $(4 \mathrm{msec})$ and congruity effects ( $7 \mathrm{msec}$ ) obtained in the remaining 14 blocks of trials $[F(1,11)=7.08, p=.02$, and $F(1,11)$ $=6.05, p=.03$, respectively]. Had we tested performance in only a single block, as is typically done in investigations of this sort, we might have concluded that Stroop dimensions strongly interact. The present results thus underscore the importance of testing dimensional pairs extensively in order to determine whether crosstalk between any given pairs of dimensions is mandatory or optional. The fact that the initial strong pattern of interaction obtained with Stroop dimensions evaporated across blocks of trials suggests that, even if semantic crosstalk underlies Stroop interaction, such crosstalk is temporary or optional. ${ }^{2}$
Melara (1989a) paired the synesthetically corresponding dimensions of color (white and black) and pitch (high and low) and tested color discriminations across 10 blocks of trials. Like Experiment 5 (corresponding dimensions), but unlike the present experiment with Stroop dimensions, Melara found no decrement in Garner interference across blocks. In Melara's experiment, as in the present experiment, color discrimination was tested, and the color dimension was paired with an irrelevant dimension that either matched or mismatched in meaning. Why then did the pattern obtained with his corresponding dimensions differ from that obtained here with Stroop dimensions? One possibility, admittedly ad hoc, is that some idiosyncratic characteristic of the traditional Stroop dimensions allowed the subjects to invoke a strategy that minimized the interference from the irrelevant dimension. For example, the subjects in Experiment 6 might have discovered that they would suffer much less linguistic interference when discriminating colors if they focused their eyes on one letter (or part) of the color word or if they otherwise attempted to avoid reading the word. Although this strategy might have been effective in Experiment 6, it probably would not have enjoyed much success in Experiment 5 , because linguistic and nonlinguistic dimensions are closely intertwined in speech. By the same token, with the dimensions of color and pitch (Melara, 1989a), focusing on smaller patches of color would not reduce the effect of the irrelevant auditory attributes.

The question of whether processing of the traditional Stroop dimensions is indeed more amenable (relative to corresponding dimensions) to strategic influences is an open one, and one that must await systematic study (e.g., of changes in eye position over blocks of trials). Now we can say only that when one directly compares corresponding dimensions (Experiment 5; Melara, 1989a) with Stroop dimensions (Experiment 6), one finds qualitatively different patterns of performance that presumably reflect qualitatively different underlying processes. Correspondence interaction is rooted in mandatory processes, we argue, because it is undiminished across blocks of trials. In contrast, Stroop interaction is ephemeral. We conclude, therefore, that correspondence interaction represents a unique form of dimensional interaction, displaying a pattern in Garner's paradigm that is distinct from integrality (Garner \& Felfoldy, 1970), configurality (Pomerantz, 1986), or Stroop interaction (cf. Stroop, 1935).

\section{GENERAL DISCUSSION}

In this study, we have shown that corresponding linguistic-nonlinguistic pairs interact symmetrically in speeded classification. Both Garner interference and congruity effects were found in both members of each pair. These effects were undiminished across as many as 15 blocks of trials. We interpret these results as reflecting bidirectional crosstalk within a semantic level of processing (depicted in Panel B of Figure 1). We base this interpretation on our assumption that findings of both Garner 
interference and congruity effects in both the linguistic and the nonlinguistic dimensions most probably are due to the extraction of meaning from attributes on these dimensions, with the output from these semantic analyses being fed through an open channel of communication between the two processing channels.

To maintain that our results instead reflect crosstalk within a sensory/perceptual level, we would need to suppose that perceptual properties of the linguistic attributes interacted with perceptual properties of the nonlinguistic attributes, in a fashion similar presumably to the interaction of visual and auditory intensity in infants (Lewkowicz \& Turkewitz, 1980). With the dimensions words and pitch (Experiments 4 and 5), for example, one might argue that sensory/perceptual crosstalk occurred between phonetic pitch in the linguistic channel (e.g., second-formant frequency of the vowels) and acoustic pitch (fundamental frequency) in the nonlinguistic channel. Recent evidence of ours (Melara \& Marks, 1990a) indicates that this particular explanation is unsatisfactory, because symmetric interaction between corresponding linguistic-nonlinguistic pairs still obtains when phonetic pitch is held constant. In general, the hypothesis of sensory/perceptual crosstalk lacks parsimony, because each new pair of linguistic-nonlinguistic dimensions requires its own unique set of critical sensory/perceptual characteristics. In the present study, for example, four such sets must be specified, one for each interaction we have found. We therefore find the sensory/perceptual account unconvincing for the dimensions tested here. Other reasons for discounting the sensory/perceptual account of the present findings are discussed later.

The present results imply that corresponding dimensions can be processed within a semantic level. Nevertheless, we do not deny that other correspondence interactions may occur within a sensory/perceptual level. Indeed, the existence of such interactions in preverbal infants would appear to demand such an explanation. Nor do we deny the possibility that, for any given pair of dimensions, crosstalk may occur both within a sensory/perceptual level and within a semantic level. Results of a recent study of ours (Melara \& Marks, 1990c) would seem best explained by this view: In testing speeded classification of the auditory dimensions pitch and loudness, we found symmetric Garner interference and redundancy gains to both positively and negatively correlated dimensions (see also Grau \& Kemler Nelson, 1988). This pattern is identical to that found with saturation and brightness of colors and so argues for sensory/perceptual crosstalk (see Garner, 1974b; Grau \& Kemler Nelson, 1988; Wood, 1975). However, we also found substantial effects of congruity, with subjects responding faster to high-pitched loud or low-pitched soft sounds than to high-pitched soft or low-pitched loud sounds. These effects argue for semantic crosstalk (but see Melara \& Marks, 1990d). In the case of pitch and loudness, then, it is not implausible to posit that two types of crosstalk operate together.
With the pairs of dimensions discussed thus far, crosstalk appears to occur within one or another level of processing. For other pairs of dimensions, however, crosstalk is explained best as occurring across levels of processing and directed either upstream or downstream. Wood's (1975) finding of asymmetric interaction between consonants and pitches (Garner interference only in consonants) is consistent with a model of upstream crosstalk from a sensory/perceptual level to a phonemic/graphemic level. Melara and Marks (1990a) tested several pairs of dimensions that apparently crosstalk downstream between these two levels.

Examples of interaction between levels of a linguistic and a nonlinguistic channel may be construed as fundamentally distinct from the directions and levels of crosstalk found in this study. Melara and Marks (1990a, Experiment 3), for example, tested acute (high-pitched) vowels (e.g., [ar], as in "pie") and grave (low-pitched) vowels (e.g., [o], as in "toe") spoken either loudly or softly. Attributes on these dimensions can be said to correspond as attributes from nonlinguistic pitch and loudness do, namely, high pitch with loud and low pitch with soft (cf. Jakobson, 1968; Jakobson, Fant, \& Halle, 1952; Jakobson \& Waugh, 1979). One might predict, therefore, that vowels and loudness would interact like pitch and loudness. We found instead a completely different pattern: Varying spoken vowels interfered greatly with loudness classification, but varying loudness had no effect on vowel classification. Moreover, neither the vowel nor the loudness dimension displayed an effect of congruity. These results indicate that spoken vowels and loudness, unlike pitch and loudness, crosstalk unidirectionally. More importantly, unlike the dimensions tested here, there is no evidence to suggest that vowels and loudness interact at a semantic level. These results are important, because they suggest that sensory/perceptual characteristics of linguistic dimensions cause a pattern of interaction qualitatively different from that found in the present study. Here, then, is another reason to discount a sensory/perceptual explanation of the present results.

\section{The Case Against Blob}

According to traditional models of dimensional interaction, failure of selective attention in filtering tasks is attributable to an initial failure to recognize the separate constituents of a multidimensional stimulus. Instead, the stimulus is perceived as an unanalyzed point ("blob") in psychological space. This holistic view seems plausible enough when considering some pairs of dimensions-for example, saturation and brightness of colors (Garner \& Felfoldy, 1970) or pitch and loudness of vibrations (Taylor, 1977)-because subjects often show difficulty understanding what distinguishes one dimension from another. But the idea of complete holistic processing is appreciably less attractive when extended to the dimensions studied here. A linguistic dimension differs qualitatively from a nonlinguistic one. It is unlikely that subjects fail to 
differentiate such dimensions, especially when the dimensions are processed through separate sensory modalities (but see McGurk \& MacDonald, 1976). Consider pitch and visually presented words, the dimensions tested in Experiment 1 . By the strong version of the holistic model, the subjects in this experiment should have been unable to distinguish what they saw from what they heard. At a phenomenal level at least, this obviously did not occur.

However, what may occur is a confusion (competition) between the linguistic code for the visual attribute and that for the auditory attribute. All of the dimensions tested in these experiments had in common the attribute labels "high" and "low." Garner interference could therefore be due to an inability to mentally segregate labels belonging to different dimensions and, in the case of Experiment 1 , labels belonging to different sensory modalities. According to one possible hypothesis, then, codes for attribute labels are partially amodal, that is, lacking complete reference to the sensory modality from which they derive. The difficulty in segregating labels leads to confusion in classification when two labels mismatch. Garner interference is thus a measure of degree of confusion assigning labels to dimensions.

In this sense, subjects are failing to discriminate a visual attribute from an auditory one (see also Long, 1977). Notice, however, that even if one accepts this account, failure of discrimination must occur at a lexical or later (i.e., semantic) level, and not at a sensory/perceptual level, because the coding of such words as "high" or "low" is a linguistic act. Subjects do not fuse together the visual and auditory dimensions. Rather, they have difficulty disentangling different linguistic codes from those dimensions. The notion of blob, then, at least as it was originally conceived, does not apply to the interactions found in this study.

\section{Processes Underlying \\ Nonlinguistic Correspondences}

Our results indicate that Garner interference need not be the by-product of only sensory/perceptual processes. To the best of our knowledge, the present experiments represent the first clear cases of Garner interference arising from semantic mechanisms. Given that the Garner interference found here was semantically based, perhaps other cases of semantic crosstalk also exist. Such instances most likely reside with those dimensions displaying the prototypical form of interaction reported here: sustained effects of congruity, symmetric interference from orthogonal variation, and gain from positively correlated variation. The fact that nonlinguistic pairs of corresponding dimensions exhibit this identical pattern suggests that such interactions may also entail semantic crosstalk. This hypothesis seems particularly compelling in the case of the synesthetically corresponding dimensions of vertical position and pitch (Melara \& O'Brien, 1987), because these dimensions, like the dimensions tested in this study, share labels to describe dimensional attributes. But the hypothesis may also apply to cross-modal dimensions that use different attribute labels (e.g., color and pitch; see Melara, 1989a) and even to unimodally corresponding dimensions (e.g., position and direction; see Clark \& Brownell, 1976), because both types of corresponding dimensions yield the prototypical pattern of results.

There is, of course, one common denominator across all interactions producing the prototypical pattern: Attributes from these pairs of dimensions are judged by independent raters to correspond meaningfully with each other (Marks, 1974; Melara, 1989b). Meaningful correspondence is presumably at the root of the congruity effects obtained with these dimensions. This common denominator is necessary but not sufficient, however, because Stroop dimensions also correspond meaningfully but lead to a pattern of results unlike the prototypical one. Nonetheless, it seems reasonable to posit that the meaningfully corresponding dimensions that exhibit the prototypical pattern are processed alike. More systematic study is obviously required, however, before we may draw this conclusion with confidence.

\section{Causes of Garner Interference}

Garner (1974b; Garner \& Felfoldy, 1970) began with a distinction between integral and separable dimensions. He believed that a pair of dimensions was integral if both dimensions were logically necessary in order for the percept to exist-a sound, for example, requires both a frequency (pitch) and an intensity (loudness). On the basis of this explanation, separable dimensions were those that did not require each other to exist (e.g., cross-modal dimensions). Indeed, investigators (e.g., Garner, 1974a; Treisman, 1969) assumed that if any pair of dimensions were likely to be separable, it would be a cross-modal pair. Of course, it is now clear that certain cross-modal dimensions can produce substantial Garner interference in speeded classification (Melara, 1989a; Melara \& O'Brien, 1987). Thus, Garner's original, strong distinction regarding what sorts of dimensions cause Garner interference is untenable. Two dimensions may interact even if one is unnecessary for the other to exist.

The worry that one can never be certain about what type of dimensions causes Garner interference is magnified by the present results: In demonstrating symmetric interactions with linguistic dimensions, we are led to question what type of processes underlies dimensional interactions. Originally, Garner interference was thought to be an effect useful for studying processes in perception (e.g., Garner, 1974b, 1983), what we have called sensory/ perceptual crosstalk. This may still be true, but the present results suggest that Garner interference alone does not distinguish sensory/perceptual crosstalk from other kinds of crosstalk. The typical amounts of interference obtained with corresponding dimensions (semantic crosstalk) fall well within the range obtained with integral dimensions (sensory/perceptual crosstalk). Thus, the absolute magnitude of Garner interference does not appear to be a valid indicator of whether crosstalk is perceptual. Moreover, as we demonstrated in Experiment 5, Garner interference 
is at least as stable in correspondence interaction as in integral interaction (see also Melara, 1989a). The point is that Garner interference is a limited diagnostic of dimensional interaction: Finding Garner interference may indicate that channels interact, but it does not indicate at what level(s) they interact.

Another diagnostic of dimensional interaction that appears unhelpful in identifying directions and levels of crosstalk is what metric determines distance in the stimulus space. Like integral dimensions, similarity ratings of stimuli formed from corresponding dimensions lead to a Euclidean metric in stimulus scaling procedures (e.g., Melara, 1989b). To the extent that integral and corresponding dimensions emerge from different processes, as we have suggested here, the Euclidean metric alone is of little value in understanding the different mechanisms underlying these interactions.

The foregoing discussion leads us to two conclusions: (1) understanding how dimensions interact means first specifying the level(s) of processing at which any given interaction occurred, and (2) the Garner interference measure alone is severely limited in its ability to inform us about how dimensions interact. Fortunately, as we have shown here, analytic devices do exist to help determine the nature of crosstalk. One device is to examine the effects of congruity in tandem with Garner interference. Another device is to select dimensions for testing judiciously, in order to maximize the chances of isolating a particular level of processing (i.e., phonemic, lexical, etc.). Our hope is to expand the analytic repertoire and to employ these tools more widely (see Melara \& Marks, 1990a), because we believe that, as a first step toward understanding how dimensions interact, one must identify the different possible forms of crosstalk.

\section{REFERENCES}

Calkins, M. W. (1895). Synaesthesia. American Journal of Psychology, 7, 90-107.

Clark, H. H., \& Brownell, H. H. (1975). Judging up and down. Journal of Experimental Psychology: Human Perception \& Performance, 1, 339-352.

Clark, H. H., \& Brownell, H. H. (1976). Position, direction, and their perceptual integrality. Perception \& Psychophysics, 19, 328-334.

DAY, R. S., \& WooD, C. C. (1972). Interactions between linguistic and nonlinguistic processing. Joumal of the Acoustical Society of America, 51, 79.

DYER, F. N. (1971). A comparison of chromatic and achromatic versions of the Stroop color-word test. Psychonomic Science, 22, 235-237.

Dyer, F. N. (1973). The Stroop phenomenon and its use in the study of perceptual, cognitive, and response processes. Memory \& Cognition, 1, 106-120.

Foard, C. F., \& Kemler Nelson, D. G. (1984). Holistic and analytic modes of processing: The multiple determinants of perceptual analysis. Journal of Experimental Psychology: General, 113, 94-111.

GARNER, W. R. (1974a). Attention: The processing of multiple sources of information. In E.C. Carterette \& M. P. Friedman (Eds.), Handbook of perception (Vol. 2, pp. 23-59). New York: Academic Press.

GARNER, W, R. (1974b). The processing of information and structure. Potomac, MD: Erlbaum.

GARNER, W. R. (1976). Interaction of stimulus dimensions in concept and choice processes. Cognitive Psychology, 8, 98-123.

GARNER, W. R. (1981). The analysis of unanalyzed perceptions. In
M. Kubovy \& J. R. Pomerantz (Eds.), Perceptual organization (pp. 119-139). Hillsdale, NJ: Erlbaum.

GaRner, W. R. (1983). Asymmetric interactions of stimulus dimensions in perceptual information processing. In T. J. Tighe \& B. E. Shepp (Eds.), Perception, cognition, and development: Interactional analyses (pp. 1-37). Hillsdale, NJ: Erlbaum.

Garner, W. R., \& Felfoldy, G. L. (1970). Integrality of stimulus dimensions in various types of information processing. Cognitive Psychology, 1, 225-241.

Grau, J. W., \& Kemler Nelson, D. G. (1988). The distinction between integral and separable dimensions: Evidence for the integrality of pitch and loudness. Joumal of Experimental Psychology: General, 117, 347-370.

Handel, S., \& Imai, S. (1972). The free classification of analyzable and unanalyzable stimuli. Perception \& Psychophysics, 12, 108-116.

Hornbostel, E. M. von (1927). The unity of the senses. Psyche, 7, 83-89.

HYMAN, R., \& WELl, A. (1967). Judgments of similarity and spatial models. Perception \& Psychophysics, 2, 233-248.

Hyman, R., \& WELL, A. (1968). Perceptual separability and spatial models. Perception \& Psychophysics, 3, 161-165.

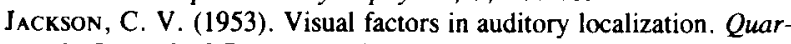
terly Journal of Experimental Psychology, 37, 52-65.

JAKOBSON, R. (1968). Child language, aphasia, and phonological universals. The Hague: Mouton.

Jakobson, R., Fant, G., Halle, M. (1952). Preliminaries to speech analysis. Cambridge, MA: MIT Press

JAKOBSON, R., \& WAUGH, L. (1979). The sound shape of language. Bloomington, IN: Indiana University Press.

Karwoski, T. F., \& Odbert, H. S. (1938). Color-music. Psychological Monographs, 50(2, Whole No. 22).

KEMLER, D. G. (1983a). Exploring and reexploring issues of integrality, perceptual sensitivity, and dimensional salience. Journal of $E x$ perimental Child Psychology, 36, 365-379.

KEMLER, D. G. (1983b). Holistic and analytic modes in perceptual and cognitive development. In T. Tighe \& B. E. Shepp (Eds.), Perception, cognition, and development: Interactional analyses (pp. 77-102). Hillsdale, NJ: Erlbaum.

Kemler Nelson, D. G. (1989). The nature and occurrence of holistic processing. In B. E. Shepp \& S. Ballesteros (Eds.), Object perception: Structure and process (pp. 357-386). Hillsdale, NJ: Erlbaum.

KLEIN, G. S. (1964). Semantic power measured through interference of words with color-naming. American Journal of Psychology, 77, 576-588.

Lewkowicz, D. J., \& Turkewitz, G. (1980). Cross-modal equivalence in early infancy: Auditory-visual intensity matching. Developmental Psychology, 16, 597-607.

LOCKHEAD, G. R. (1966). Effects of dimensional redundancy on visual discrimination. Journal of Experimental Psychology, 72, 95-104.

Lockhead, G. R. (1972). Processing dimensional stimuli: A note. Psychological Review, 79, 410-419.

LOCKHEAD, G. R. (1979). Holistic versus analytic process models: A reply. Journal of Experimental Psychology: Human Perception \& Performance, 5, 746-755.

LOGAN, G. D. (1980). Attention and automaticity in Stroop and priming tasks: Theory and data. Cognitive Psychology, 12, 523-553

LoNG, J. (1977). Contextual assimilation and its effect on the division of attention between nonverbal signals. Quarterly Journal of Experimental Psychology, 29, 397-414.

LURIA, A. R. (1968). The mind of a mnemonist. New York: Basic Books.

MARKs, L. E. (1974). On associations of light and sound: The mediation of brightness, pitch, and loudness. American Journal of Psychology, 87, 173-188.

MaRKS, L. E. (1975). On colored-hearing synesthesia: Cross-modal translations of sensory dimensions. Psychological Bulletin, 82, 303-331.

Marks, L. E. (1987). On cross-modal similarity: Auditory-visual interactions in speeded discrimination. Journal of Experimental Psychology: Human Perception \& Performance, 13, 384-394.

Marks, L. E., Hammeal, L. J., \& Bornstein, M. H. (1987). Perceiving similarity and comprehending metaphor. Monographs of the 
Society for Research in Child Development, 52(1, Serial No. 215), pp. 1-93

MCCLAIN, L. (1983). Stimulus-response compatibility affects auditory Stroop interference. Perception \& Psychophysics, 33, 266-270.

MCGuRK, H., MaCDonald, J. (1976). Hearing lips and seeing voices. Nature, 264, 746-748.

MElaRA, R. D. (1989a). Dimensional interaction between color and pitch. Joumal of Experimental Psychology: Human Perception \& Performance, 15, 69-79.

Melara, R. D. (1989b). Similarity relations among synesthetic stimuli and their attributes. Joumal of Experimental Psychology: Human Perception \& Performance, 15, 212-231

Melara, R. D., \& Marks, L. E. (1990a). Dimensional interactions in language processing: Investigating directions and levels of crosstalk. Joumal of Experimental Psychology: Leaming, Memory, \& Cognition, 16, 539-554.

Melara, R. D., \& Marks, L. E. (1990b). HARD and soft interacting dimensions: Differential effects of dual context on classification. Perception \& Psychophysics, 47, 307-325.

Melara, R. D., \& Marks, L. E. (1990c). Perceptual primacy of dimensions: Support for a model of dimensional interaction. Journal of $E x$ perimental Psychology: Human Perception \& Performance, 16. 398-414.

Melara, R. D., Marks, L. E. (1990d). Interaction among auditory dimensions: Timbre, pitch and loudness. Perception \& Psychophysics, 48, 169-178.

Melara, R. D., \& O'Brien, T. P. (1987). Interaction between synesthetically corresponding dimensions. Journal of Experimental Psychology: General, 116, 323-336.

Melara, R. D., \& O'Brien, T. P. (1990). Effects of cuing on crossmodal congruity. Journal of Memory \& Language.

Nissen, M. J. (1985). Accessing features and objects: Is location special? In M. I. Posner \& O. S. Marin (Eds.), Attention and Performance $X I$ (pp. 205-219). Hillsdale, NJ: Erlbaum

Odbert, H. S., Karwoski, T. F., \& Eckerson, A. B. (1942). Studies in synaesthetic thinking: I. Musical and verbal association of color and mood. Journal of General Psychology, 26, 153-173.

Ortmann, O. (1933). Theories of synaesthesia in the light of a case of color-hearing. Human Biology, 51, 155-211.

Pick, H. L., JR., WarRen, D. H., \& HaY, J. C. (1969). Sensory conflict in judgments of spatial direction. Perception \& Psychophysics, 6, 203-205

Pomerantz, J. R. (1983). Global and local precedence: Selective attention in form and motion perception. Journal of Experimental Psychology: General, 112, 515-540.

Pomerantz, J. R. (1986). Visual form perception: An overview. In E. C. Schwab \& H. C. Nusbaum (Eds.), Pattern recognition by humans and machines: Visual perception (pp. 1-30). New York: Academic Press.

Pomerantz, J, R., \& Garner, W. R. (1973). Stimulus configurations in selective attention tasks. Perception \& Psychophysics, 14, 565-569.

Pomerantz, J. R., \& Pristach, E. A. (1989). Emergent features, attention, and perceptual glue in visual form perception. Journal of $E x-$ perimental Psychology: Human Perception \& Performance, 15. 635-649.

Pomerantz, J. R., Pristach, E. A., \& Carson, C. E. (1989). Attention and object perception. In B. E. Shepp \& S. Ballesteros (Eds.), Object perception: Structure and process (pp. 53-89). Hillsdale, NJ: Erlbaum.

Price, J. M. (1979). Software timing for 6500 series microcomputers. Behavior Research Methods \& Instrumentation, 11, 568-571.

PritchatT, D. (1968). An investigation into some of the underlying associative verbal processes of the Stroop colour effect. Quarterly Jour nal of Experimental Psychology, 20, 351-359.

RigGs, L. A., \& KARWOSKI, T. (1934). Synaesthesia. British Journal of Psychology, 25, 29-41.

Seymour, P. H. K. (1974). Stroop interference with response, comparison, and encoding stages in a sentence-picture comparison task. Memory \& Cognition, 2, 19-26

SHEPP, B. E. (1989). On perceiving objects: Holistic versus featural properties. In B. E. Shepp \& S. Ballesteros (Eds.), Object perception: Structure and process (pp. 203-233). Hillsdale, NJ: Erlbaum.

Smith, L. B., Kemler, D. G. (1977). Developmental trends in free classification: Evidence for a new conceptualization of perceptual development. Journal of Experimental Child Psychology, 24, 279-298.

SMITH, L. B., \& KEMLER, D. G. (1978). Levels of experienced dimensionality in children and adults. Cognitive Psychology, 10, 502-532.

STROOP, J. R. (1935). Studies of interference in serial verbal reaction. Journal of Experimental Psychology, 18, 643-662.

TAYLOR, B. (1977). Dimensional interactions in vibrotactile information processing. Perception \& Psychophysics, 21, 477-481.

TORGERSON, W. S. (1958). Theory and methods of scaling. New York: Wiley

Treisman, A. M. (1969). Strategies and models of selective attention. Psychological Review, 76, 282-299.

Treisman, A. M., \& Fearnley, S. (1969). The Stroop test: Selective attention to colours and words. Nature, 222, 437-439.

VIRZ1, R. A., \& EGETH, H. E. (1985). Toward a translational model of Stroop interference. Memory \& Cognition, 13, 304-319.

VON WRIGHT, J. M. (1970). On selection in visual immediate memory. Acta Psychologica, 33, 280-292.

Wagner, S., Winner, E., Cicchetti, D., \& Gardner, H. (1981). "Metaphorical" mapping in human infants. Child Development, 52. 728-731

WALKER, P., \& SMITH, S. (1984). Stroop interference based on the synaesthetic qualities of auditory pitch. Perception, 13, 75-81.

WALKeR, P., \& SMITH, S. (1986). The basis of Stroop interference involving the multimodal correlates of auditory pitch. Perception, 15, $491-496$.

WERNER, H. (1940). Comparative psychology of mental development. New York: International Universities Press

Wood, C. C. (1974). Parallel processing of auditory and phonetic information in speech discrimination. Perception \& Psychophysics, 15. 501-508.

Woon, C. C. (1975). Auditory and phonetic levels of processing in speech perception: Neurophysiological and information-processing analyses. Joumal of Experimental Psychology: Human Perception \& Performance, 1, 3-20.

WRIGHT, R. D. (1986). Amiga 1000 hardware timing and reaction-time key interfacing. Behavior Research Methods, Instruments, \& Computers, 18, 463-465

\section{NOTES}

1. Another exception is the somewhat lower correlation between speed and accuracy obtained in this experiment, compared with that obtained in Experiment 1. The difference seems to be due to the fact that there were fewer errors made in the filtering tasks tested here than there were in Experiment 1. In terms of the statistical analyses performed, however, the pattern of errors in the two experiments were virtually indistinguishable. And, of course, in both experiments the speed-accuracy correlation was positive, suggesting that no severe speed-accuracy tradeoff was operating in either experiment to jeopardize our interpretation of RTs. Given the relatively small number of errors obtained in all experiments reported in this article-and, consequently, the instability inherent in this measure-we prefer to downplay the importance of slight inconsistencies in error data and to concentrate instead on the more robust RT data.

2. It is likely that the processes underlying the Stroop interaction that we report here differ in important ways from those underlying traditional Stroop interference in color-naming responses. We might expect, therefore, that traditional Stroop interference with these dimensions would not diminish across blocks of trials, as did Garner interference and congruity effects. Our point, however, is that, when compared directly in the speeded classification procedure, Stroop dimensions interact differently from corresponding dimensions.

(Manuscript received June 29, 1989; revision accepted for publication March 20, 1990.) 